\section{A vontade de potência do prossumidor: uma análise da vontade e da força da vontade nas práticas dos potterheads}

\author{
Flávia Zimmerle da Nóbrega Costa e André Luiz Maranhão de \\ Souza-Leão
}

\section{RESUMO}

A sociedade da informação instaurou condições de existência interligadas, transformou os modos de sociabilidade e de trocas econômicas e culturais. Nesse cenário, surgiram as comunidades de fãs de textos culturais. Harry Potter tornou-se um potente texto cultural contemporâneo e, apesar do término da saga, seus fãs continuam ativos. Entendendo-os como consumidores produtivos, tomamos o pensamento deleuziano para assumir seu corpo como sendo estabelecido e dinamizado por um processo em que a vontade de potência é uma força operada por meio do espaço relacional do afeto e o espaço temporal da memória. Com base nisso, a pesquisa foi orientada pela seguinte questão investigativa: como o consumo produtivo dos potterheads se caracteriza em relação à sua vontade de potência? Para realiza-la, adotamos a Análise de Discurso Foucaultiana, com base em um arquivo de dados documentais, coletados em mídias digitais. A pesquisa revelou uma formação discursiva referente a como a vontade de potência dos potterheads oscila de acordo com a natureza de suas ideias, que depende da seleção de encontros que fazem: ideias que se afirmam como tristeza fazem oscilar negativamente sua vontade de potência, que varia positivamente mediante ideias afirmadas como alegria.

Palavras-chave: potterheads; prossumo; vontade de potência; Deleuze.

The prosumer's will of power: an analysis of the will and willpower in the potterheads practices

\section{ABSTRACT}

The information society has introduced interconnected living conditions, transformed the ways of sociability and economic and cultural exchanges. In this scenario, cultural texts of fans communities have appeared. Harry Potter has become a powerful contemporary cultural text, and, despite the end of the saga, the fans remain active. Understanding them as productive consumers, we take the Deleuzian thought to assume their body to be established and boosted by a process in which the will to power is a force operated by the relational space of affection and the temporal space of memory. Based on this, the research was guided by the following investigative question: how potterheads' productive consumption is characterized concerning its will to power? To undergone it, we adopted the Foucauldian Discourse Analysis, based on a documentary data archive collected on digital media. The research revealed a discursive formation as how the will to power of potterheads fluctuates according to the nature of their ideas, which depend on the selection of meetings that they do, such as: ideas that affirm themselves as sadness make them oscillate negatively in their will to power, which varies positively through ideas affirmed as joy.

Keywords: potterheads; prosumption; will to power; Deleuze.

Recebido em: 25/07/2017 Revisado em: 29/12/2017 Aprovado em: 03/10/2018

Check for updates

Flávia Zimmerle da Nóbrega Costa (D), Universidade Federal de Pernambuco, Brasil Doutorado em Administração

flaviazimmerle@hotmail.com

André Luiz Maranhão de Souza-Leão iD,

Universidade Federal de Pernambuco, Brasil Doutorado em Administração

aleao21@hotmail.com 
Introdução

O entretenimento é uma atividade econômica que se destacou pela rápida e contínua evolução alcançada nos últimos anos, cujo crescimento foi acompanhado pela indústria brasileira (International Trade Administration, 2016). Harry Potteré um produto exitoso nessa atividade, sendo considerado um dos mais potentes textos culturais já produzidos. No intervalo de 14 anos entre o lançamento do primeiro dos sete livros e o último dos oito filmes, a obra foi traduzida para mais de 60 idiomas e acessada por um número expressivo de famílias ocidentais, cujos filhos cresceram junto aos lançamentos dos produtos e aos atores da saga cinematográfica. Seus produtos continuam a manter um quantitativo expressivo de comunidades de fãs, embora já se tenha passado sete anos desde o último lançamento. A série infantil mais vendida do mundo (Bennett, 2014; Batista \& Domingos, 2011) deve muito de seu sucesso ao estabelecimento de uma sólida ligação afetiva entre o produto e seus consumidores, esses, conhecidos como potterheads.

A ligação afetiva é a economia própria da cultura participativa, que está relacionada ao consumo de produtos culturais e se estabelece por meio de uma produção colaborativa. Além disso, é particularmente constituída por uma teia relacional dada entre fãs da cultura pop, produtores culturais e tecnologias (Jenkins, 2009). Os produtos culturais propiciam a esses consumidores particulares construir suas identidades (Guschwan, 2012) e produzir significados e valores para os membros do seu espaço social de convivência (Boulaire \& Cova, 2013). Esse espaço é denominado fandom, e nele acontecem novas formas de sociabilidades e agenciamentos (Lee, 2011). Jenkins (2009) analisa que o modo como os fãs consomem e produzem transformou as formas tradicionais de produção e distribuição dessa indústria.

O fã é considerado um dos tipos de consumidor que mais fortemente tem evidenciado o papel da produção de significados e de valores nos processos de consumo (Siuda, 2014). No fandom eles criam jogos, textos e filmes, traduzem obras antes que a indústria, fazem adaptações de enredos e paródias criativas (Jenkins, 2009), disseminando sua produção nas redes sociais. A própria socialização do fã nesse espaço perpassa por um longo aprendizado, que inclui o conhecimento e os cuidados com os textos culturais (Bennett, 2014; Bronwen, 2011). A tarefa requer o investimento de tempo e esforço, além de assumpção de responsabilidades morais perante o grupo e perante o cânone, pois é preciso respeitar e cuidar da autenticidade e integridade de ambos. O diálogo intensivo que ocorre no fandom faz dele o lugar para se discutir e estabelecer entendimentos sobre a vida, desenvolver sentimentos como solidariedade e reciprocidade, além de estreitar os laços afetivos, inclusive promovendo engajamentos políticos em prol de intolerâncias, discriminações e/ou causas sociais (Bronwen, 2011; Lee, 2011; Van Zoonen, 2004).

Os fãs da cultura pop consomem e produzem conteúdo a partir dos textos culturais, construindo seus mundos a partir desse trabalho. Ao divulgar tal trabalho nas redes sociais, eles podem ou não promover o sucesso dos 
produtos (Jenkins, 2009). Nesse sentido, parcerias já foram criadas entre audiência e produção (Chin, 2014; Van Zoonen, 2004) sendo a potencialidade desse tipo de trabalho também de conhecimento do consumidor (Amaral, Souza, \& Monteiro, 2015; Jenkins, 2009; Spaaij \& Viñas, 2013). Assim, se de um lado o comportamento dos fãs assegura o entendimento de que consumidores não devem ser mais entendidos como passivos (Stanfill \& Condis, 2014), por outro, a cocriação de significados e valores por eles produzidos nem sempre beneficiam produtos e identidades de marcas. A ação dos consumidores-produtores tanto impulsiona um aumento de audiência como influencia sua drástica queda (Anderson \& Hamilton, 2016; Kähr; Nyffenegger, Krohmer, \& Hoyer, 2016; Troye \& Supphellen, 2012).

As práticas naturais desses agentes marcam o que para alguns autores representa a quase impossibilidade de se definir os limites do que se considera consumo e produção (Eden, 2015; Ellsworth-Krebs \& Reid, 2016; Ritzer, 2013; 2015b). O processo produção-consumo observado como um continuum é designado na língua inglesa pelo termo prosumption, sendo o consumidor produtivo denominado de prosumer (Büscher, 2013; Cova \& Cova, 2012; Dujarier, 2016; Eden, 2015; Ritzer, 2013, 2015b). Desta forma, neste trabalho adotamos a tradução livre de Ritzer (2015a) para esses termos: prossumerização e prossumidor, respectivamente.

As experiências com marcas e produtos culturais são sempre sedutoras (Cova \& Cova, 2012; Jenkins, 2009) principalmente porque o comportamento do fã-prossumidor é orientado por uma relação afetiva. Para Jenkins (2009), tais práticas orientadas pelo afeto envolvem um estado de paixão, que por sua vez lhes concede uma enorme capacidade inventiva, militante e colaborativa. Considerando que a rede afetiva que liga os prossumidores Ihes impulsiona a construir e manter seu espaço social (Cova \& Cova, 2012), propomos entender como isso é possível. Entretanto, nesta pesquisa não analisaremos esse estado de paixão como alusivo ao consumo hedônico, de alto envolvimento, ou focado no desejo, tal como o fez, por exemplo, Belk, Ger e Askegaard (2003); a paixão aqui é entendida no sentido spinozista, oriunda de uma experiência vivida por um corpo recorrentemente afetado pelo mundo que, perante a mesma, aumenta ou diminui sua vontade de potência (Deleuze, 1976).

Para Spinoza (2009), os afetos são definidos pelas afecções de um corpo juntamente com suas ideias, podendo tais afetos serem ativos ou passivos. Os ativos são ações que se referem ao esforço próprio da natureza do corpo para aumentar sua potência de agir. Esses são considerados sempre afetos alegres. Os afetos pasivos, por sua vez, são paixões cujas causas proveem total ou parcialmente do mundo exterior, podendo ser alegres, se propiciam ao corpo uma potência maior de ação no mundo, ou tristes, se levam esse corpo a uma potência menor, limitando sua capacidade de afetar e ser afetado. Assim como suas causas são impostas ao corpo, as paixões são afetos inconstantes que promovem a flutuação do ânimo no interior de uma ordem de encontros que lhes são conveninetes ou incovenientes. Os bons encontros - afetos alegres - aumentam a potência de pensar e o conhecimento, assim como geram noções comuns, que facilitam a escolha dos encontros alegres e a ação de afetar e ser afetado. 
Sendo o corpo uma potência de existir, a vontade é definida por Spinoza (2009) como sendo o esforço e a consciência desse esforço efetuado para preservação do ser. Na filosofia de Gilles Deleuze o conceito de vontade de potência é parte de um projeto de tornar-se ativo, uma construção em que Henri Bergson e Friedrich Nietzsche são trazidos para a leitura de Baruch Spinoza; nessa, uma paixão alegre (externalidade) pode tornar-se uma ideia adequada (imanência), e a seleção dos encontros é uma questão de ética e potencialidade (Hardt, 1996). Para Deleuze $(1978,2002,2005)$ o presente é, ao mesmo tempo, um passado e um futuro. Segundo o autor, o real é uma produção do agenciamento de sujeitos, efetuada mediante as suas vontades, mas dependente da força com que as mesmas se estabelecem no corpo social. Para o filósofo, cabe à vontade de potência operar essa força política, estabelecendo tal vontade nesse corpo social. A vida é aqui concebida como uma relação permanente entre forças, cujo combate não apresenta a dominância de uma sobre as outras, mas estabelece uma diferença. A vontade de potência é uma espécie de combustível que faz as forças lutarem entre si constantemente por se manifestar nesse embate como um 'querer-vir-a-ser-mais-forte' (Souza, Junquilho, Machado, \& Bianco, 2006). Portanto, a vontade de potência é criadora e dotada de qualidades contrárias: afirmação e negação (Deleuze, 1976). A negação refreia a força, mas a afirmação é imanente, tem base ética, pois constitui-se do que é querido. Valorativa e produtiva, a mesma sempre antecede o ser no tempo, construindo o atual em coexistência com um virtual.

O sucesso de Harry Potter pode ser certificado pela continuidade de seu fandom, o que, partindo do pensamento deleuziano, pode ser entendido pela qualidade e quantidade do trabalho afetivo e incansável praticado pelos potterheads. Nesta linha de raciocínio, esse espaço social se configura como um corpo cuja natureza é composta por um limiar de intensidades que varia de modo intermitente e de acordo com as ideias que possui. Ao tomar forma nesta prática, a ética revela os saberes/ideias que compõem o limiar de intensidades a que esse corpo está exposto. Sendo assim, nos questionamos: Como o consumo produtivo dos potterheads se caracteriza em relação à sua vontade de potência?

Corroboramos com o pensamento de que estudiosos do marketing deveriam estar mais atentos ao desempenho do prossumidor em meio às mudanças causadas pelos avanços tecnológicos. Ademais, é necessário que seja observado seu processo produtivo de significados, seja seu modus operandi caracterizado pelo alto envolvimento com produtos e/ou serviços, ou ainda sua capacidade de desempenho ou potencial criativo e afetivo (Ritzer, 2015a, 2015b). Tais estudos têm ganhado importância na abordagem Consumer Culture Theory (CCT). Embora a CCT comporte diferentes vertentes de estudos do consumidor, ela abre um leque de possibilidades para essas discussões em suas linhas de pensamento (Earley, 2014; Heilbrunn, 2015; Moisander, Valtonen \& Hirsto, 2009). Apoiados na crítica pós-estruturalista, partimos do entendimento de que verdade e valores são imanentes, que o agente ou sujeito é subjetividade pura e se constrói junto aos objetos em sua processualidade (Williams, 2012). Pautados nesse pensamento, buscamos o apoio na filosofia deleuziana para nossa compreensão acerca da prática do fã, um prossumidor particular, pela força com que evidencia o processo (Siuda, 2014). 
Esperamos que nosso trabalho contribua com os estudos críticos do prossumidor na CCT, uma vez que o processo de prossumerização pode ser revelado em sua forma mais pura pelo trabalho afetivo dos fãs (Siuda, 2014), entretanto, muito ainda se tem para explorar acerca do modo como acontecem suas várias funções cooperativas (Roberts, 2017). Apoiados na filosofia deleuziana, assumimos que a produção de "quereres" dada no processo de prossumerização é uma prática transformadora pertinente aos novos cenários sociais, cujo motor é uma força que surge e se efetiva pautada em uma vontade ética (imanente) e em uma força de vontade que é afetiva (Deleuze, 1976).

\section{Os estudos do prossumidor na Consumer Culture Theory}

A disseminação da internet como plataforma para interação entre consumidores e produtores inflamou as discussões acerca do comportamento de um consumidor ativo e criativo, cuja competência o torna coprodutor de valor para produtos e serviços pelos quais se interessa por meio de um trabalho efetuado de forma voluntária e autônoma (Cova \& Cova, 2012; Rey, 2012).

Tais consumidores e suas formas de produção são objetos de interesse de estudiosos da Consumer Culture Theory (CCT), uma abordagem da pesquisa do consumidor formada por diferentes perspectivas teóricas, mas que reconhece a cultura como o cerne para realização da experiência, ação e significação no consumo (Arnould \& Thompson, 2005). Em geral, esse corpo de perspectivas carrega em comum o apoio na epistemologia interpretativista e o uso de métodos qualitativos (Casotti \& Suarez, 2016; Gaião, Souza, \& Leão, 2012), sendo também encontradas vertentes do pensamento crítico, entre elas, do movimento pós-estruturalista (Earley, 2013; Heilbrunn, 2015; Moisander, et al., 2009). Nos estudos da CCT cabe à temática de culturas de mercado buscar o entendimento de como a cultura de consumo é produzida e de que modo impacta a vida das pessoas (Arnould \& Thompson, 2005).

Para Cova e Cova (2012) a conquista da competência de atuação do consumidor foi revelada pelos próprios discursos de marketing dos últimos trinta anos, ao mesmo tempo em que ajudaram a criar faces para esse sujeito. Segundo os autores, no marketing de relacionamento o consumidor individualista desenvolveu a capacidade de dialogar com empresas; no marketing experiencial o consumidor hedonista capacitou-se na produção de experiências buscando o prazer em seus atos de consumo; no marketing colaborativo, o consumidor criativo tornou-se um parceiro do produtor por sua habilidade em cocriar valor para produtos e serviços.

Desse modo, de acordo com a perspectiva analítica, é comum o consumidor ser entendido como empoderado (Jenkins, 2009) e como um colaborador criativo que serve a si, aos ofertantes de serviço (Vargo \& Lusch, 2004) e aos de produtos, ou ainda, em uma abordagem crítica, como um trabalhador explorado pelo sistema capitalista (Büscher, 2013; Fuchs, 2011; Roberts, 2017). O pensamento pós-estruturalista, apesar de reconhecer que 
a contribuição desse trabalhador é capturada pelo produtor, entende que em sua agência ele também promove resistência ao sistema, ao mercado e à própria ação do marketing (Beckett, 2012), utilizando inclusive do cinismo entre suas estratégias para fazê-lo (Mikkonen, Moisander, \& Firat, 2011). Contudo, salientamos que a resistência é um modo de ação sobre ações existentes que se refere a escapar e transformar o poder (sempre em atividade) a partir de seus múltiplos pontos de instabilidade (Jackson, 2013). Linstead e Thanem (2007) salientam que o desejo pode ser uma forma de resistência.

O que o contexto trazido pelas redes de comunicação e as novas formas de produção e consumo evidenciaram foi a indefinição existente entre os limites do que se considera produção ou consumo (Eden, 2015; Ellsworth-Krebs \& Reid, 2016; Ritzer, 2013, 2015b), estando nesse nebuloso delineamento a proposta fundamental do marketing colaborativo (Cova \& Cova, 2012). Corroboraram para isso a prática dos novos consumidores, suas relações sociais altamente afetadas por tecnologias e a instauração da cultura participativa (Ruckenstein, 2015). De um olhar mais sistêmico, tal reconhecimento foi influenciado pela aceitação de uma economia sobrepujada pelo consumo e pela maior valorização dos signos (Ritzer, 2015b).

O entendimento de que os processos de produção e consumo devem ser analisados em sua condição de inter-relação e simultaneidade desafiou a distinção binária que se estabeleceu historicamente, responsável pelo compromisso de análises com apenas um dos processos. Para essa linha de pensamento não existe produção sem consumo, nem consumo sem produção. O foco em um dos estremos obscurece o entendimento de uma prática que sempre ocorreu interligada (Ritzer, 2015b).

Seguindo Ritzer (2015a), o termo destinado ao entendimento do processo como um continuum é prossumerização, ou seja, a junção dos nomes (produção e consumo), exatamente por marcar a difícil tarefa de sua distinção (Cova \& Cova, 2012; Eden, 2015; Ellsworth-Krebs \& Reid, 2016). Para Ritzer, cabe ao consumidor envolvido nesse processo a designação de prossumidor.

São características do prossumidor ser proativo e prospectivo (Ritzer, 2015a), tendo em vista que, cada vez mais, esse agente vem assumindo tarefas antes avaliadas como da produção (Cova \& Cova, 2012; Dujarier, 2016; Ellsworth-Krebs \& Reid, 2016). Ao cocriarem significados em suas práticas de consumo, os prossumidores se beneficiam diretamente enquanto sujeitos sociais, mas indiretamente podem agregar valor aos produtos e marcas (Anderson, Hamilton, \& Tonner, 2016; Kähr, et al., 2016; Troye \& Supphellen, 2012). Suas práticas geram uma expressiva audiência, podendo reforçar ou desestabilizar as identidades dessas marcas (Parmentier \& Ficher, 2015; Pongsakornrungsilp \& Schroeder, 2011).

O processo de prossumerização pode ser observado em sua forma mais pura na particularidade do trabalho do fã. Sua cocriação de valor tem adquirido reconhecida importância, sendo incorporada nas orientações das estratégias de marketing em empresas de mídia e entretenimento (Siuda, 2014). O trabalho de tais prossumidores gera conteúdos para produtos culturais (Fuchs, 2011), produções que são afetivas. Segundo Roberts 
(2017), embora a disseminação de informações ainda seja para os estudiosos o papel mais importante realizado pela rede de prossumidores, as funções cooperativas, tais como a construção da comunidade, a partilha de dados e a produção colaborativa de conteúdos começam a ganhar destaque, precisando ser ainda exploradas.

\section{O pensamento deleuziano e o fã-prossumidor: conexões possíveis}

O potencial de criticidade da produção deleuziana abre possibilidades analíticas para os diversos campos da Administração, pois engendra um pensamento desengajado de contornos familiares, embasando significativas mudanças no modo de teorizar e conceituar investigações qualitativas (Masny, 2013). Assumi-lo denota a assunção de uma postura investigativa que, para além de epistemológica e metodológica é também ética, estética e política (Rolnik, 1995). Almeida (2003) analisa que o abandono da visão dualista abre o pensamento para enxergar construções intercambiáveis e recomenda que se investigue agenciamentos como conectividades entre planos heterogêneos. Tal postura de pensamento oportuniza reconsiderar uma gama de questões frente à abundância de informações digitais as quais estamos expostos, como: trabalho, criação de valor, vigilância (Zwick \& Knott, 2009), exploração, alienação (Rey, 2012), entre outras.

Tendo em mente algumas discussões acerca das práticas do prossumidor e suas consequências (Cova \& Cova, 2012; Eden, 2015; Ellsworth-Krebs \& Reid, 2016; Ritzer, 2013, 2015b, Ruckenstein, 2015; Zajc, 2015), a transcrição abaixo orientará o desenvolvimento dessa seção, permitindo estabelecer um link entre esse pensamento e as práticas do prossumidor:

Se em tudo que você quiser fazer, você começar a perguntar se deseja realizar um número infinito de vezes, isso será pra você o mais sólido da gravidade. Viva de tal modo que você queira viver o resto da sua vida desse modo, pois, dessa forma, você o reviverá (Silva, 2014, p. 167).

A citação diz respeito a uma regra deleuziana produzida a partir do ajuntamento de três aforismos nietzschianos (Silva, 2014) e trata de temas fundamentais em sua filosofia, como a vontade e a força da vontade, envolvendo conceitos acerca do ser no devir, como vontade de potência, força, ética e eterno retorno. Em Nietzsche (2011), os conceitos de vontade de poder e eterno retorno são próprios do acontecimento da vida e da ânsia pela sua intensificação. A vida e o ser do homem são entendidos como casos peculiares da vontade de poder, pois sendo uma fonte de ação em si mesma, tal vontade potencialmente permite uma transcendência no interior da imanência, contudo, para um além ainda puramente subjetivo (Tugendhat, 2002).

Os conceitos deleuzianos são multiplicidades, se apoiam mutuamente, são ferramentas que nascem no solo da imanência e possuem um devir que lhes concerne (Vasconcellos, 2010). Para desenvolver seus conceitos, o filósofo utilizou o simulacro como um protótipo para o processo de subjetivação, sendo esse detentor de um modelo epistemológico sob o qual 
se repete a simulação, mas "à semelhança e à diferença de um mundo de ordem e identidade [...]" como assim conhecemos (Madarasz, 2005, p.1214). Sua estrutura sempre volta, uma vez que compartilha de auto conservação profunda. Embora o eterno retorno nunca repita o mesmo, a cada volta ele produz a diferença pura (Corazza, 2012). O eterno retorno, apesar de ser objeto da construção deleuziana (Bergson - Nietzsche - Spinoza), traz uma ideia fundamental nietzschiana. Em Nietzsche (2011), sendo o ser e o mundo vontade de poder, a vontade torna-se o cerne essencial da existência, é constitutivamente falta e é responsável por vincular e promover ação do homem em relação ao objeto da vontade. Assim, a vontade é o que sempre volta, seja para a construção ou destruição de si mesmo, possibilitando uma abertura para a transformação do eterno por meio de um "vir-a-ser" que desconhece o cansaço e a saciedade.

Deleuze entende que a diferença é conduzida por variações intensivas e, em todo o processo intensivo, as características exógenas permanecem escondidas no produto, convivendo com um conjunto aberto de capacidades. Isso ocorre tendo em vista que os pontos críticos de limiares (capazes de mudar a estrutura de um corpo espontânea e abruptamente) são característicos das intensidades (DeLanda, 2006). Sendo assim, a diferença é sempre um ato de criação, fruto da composição de forças em determinado contexto. Rolnik (1995) a define como o que é arrebatado de nós mesmos e nos faz devir outro.

Isso diz respeito, tal como em Nietzsche (2011), ao eterno retorno como "[...] ato de afirmação da vontade" (Machado, 2011, p.141), que acontece baseado na vontade de potência, mas, devido à síntese temporal a que está sujeito, jamais retorna o mesmo (Misoczky, 2003). Para Machado (2011), a afirmação do ser no devir trata de "torna-se o que se é", mas não diz respeito a descobrir-se, mas a produzir-se a partir de uma vontade afirmativa, sendo seu próprio legislador e deliberando acerca das próprias virtudes. Rolnik (1995) esclarece que a problematização deleuziana parte da despedida do absoluto, no entanto não se refere a ocupar a posição niilista nietzschiana e posicionar "o nada", mas a colocar nessa fresta o movimento ilimitado de formas de realidade, despedindo-se de qualquer critério moral (definidor de formas a priori) e assumir um critério ético ou vital que propicia avaliar como tais formas podem fortalecer ou não a vida.

Desse modo, para Deleuze $(1976,1978,2002)$ a realidade é produzida por meio de um agenciamento no campo social pautado na vontade (o querer fazer) e na força com que se estabelece essa vontade (o poder fazer). $\mathrm{O}$ atual acontece assim em coexistência com um virtual, pois o presente é ao mesmo tempo um passado e um futuro. Assim, assumem posições relevantes em seu pensamento a memória (um espaço temporal) e o afeto (uma força, um espaço relacional).

Deleuze opta pela relação entre atual e virtual a partir da crítica ao par possível-real (Hardt, 1996; Misoczky, 2003). A diferença é concebida como uma relação entre virtual e atual, que é de imbricamento e atualização, sendo toda atualização do virtual um evento aberto e a diferença, de natureza, um efeito dessa interação constante. O atual desfruta de uma existência temporal e momentânea como evento singular (Linstead \& Thanem, 2007), 
sendo as dimensões que operam "distribuições e efetivações do virtual em atos de criação efetivos, invenção de um campo de possíveis" (Almeida, 2003, p.212). O virtual presente no atual envolve uma multiplicidade de forças e tendências heterogêneas que precedem, habitam e excedem a organização de um corpo, gozando de uma diferença interna capaz de incorporar as diversas tendências e diferenciar a si mesmo (Linstead \& Thanem, 2007). Assim, o virtual é continuamente formado e não formado. Ademais, envolve a entidade meio-virtual meio-intensiva conhecida por "linha de voo" (DeLanda, 2006). Por sua vez, organização e ordem não são sinônimos. A multiplicidade da ordem é espacial e se refere à diferença de grau, exterioridade, simultaneidade, justaposição e diferenciação quantitativa, que é descontínua e atual. A multiplicidade da organização é interioridade e se refere a diferença de tipo, discriminação qualitativa, sucessão, fusão, heterogeneidade; é virtual, contínua e irredutível a números por ser relativa ao tempo experimentado (Linstead \& Thanem, 2007).

Assim, a construção memória-tempo deleuziana apoia-se em duas cadeias não dialéticas para a diferença do ser: a externalidade determinada de ordem quantitativa e a imanência indeterminada de ordem qualitativa. O par imanente virtual-atual se refere ao princípio de transformação de uma força eficiente que estabelece uma diferença de natureza. Baseia-se numa ética ${ }^{2}$ constituída pela condição interna indeterminada, que sofreu um processo de organização. Esse processo é contínuo e nele a intuição (uma razão da experiência) aparece abastecida pela memória. Ao contrário, a força não eficiente tem por base a diferença externa determinada, promovendo uma diferença de grau a partir da ordem pré-existente (Hardt, 1996).

Nessa construção, o afeto é a força que funciona como cola em relações subjetivantes, pois advém do compartilhamento de princípios e identificações. Graças ao afeto, corpos que se descobrem convenientes estabelecem uma solidariedade política. Como força, o afeto é um modo de pensamento que não representa nada, ou seja, precisa de uma ideia ${ }^{3}$ ou modo de pensamento enquanto representativo para se estabelecer nas relações, embora não se reduza a essa ideia. Assim, o afeto se instaura na variação contínua entre o aumento e a diminuição de potência a que um corpo é submetido pelas ideias que tem (Deleuze, 1978, 2002).

Deleuze traz da filosofia prática de Espinoza as paixões alegres e tristes. Paixões são afetos passivos, inconstantes e promovem flutuação do ânimo

1 As linhas de voo se prestam à desterritorializar, experimentar, construir conceitos, produzindo outro mapeamento em um rizoma; tornar-se um processo rizomático (Masny, 2013).

2 A ética deleuziana não é da alçada de uma ordem moral, mas da capacidade de "dar ouvido" às diferenças imanentes que intempestivamente desassossegam o ser (é deixar-se afetar pelas forças de seu tempo) e delas afirmar a diferença. A relação que se assume com essa tensão insuperável define formas de ética e de política, essas indissociáveis no respeito à vida (Rolnik, 1995). Quando colocado em prática, o projeto ético torna-se político e a arte do arranjo político reúne o corpo social definido "[...] por um conjunto de comportamentos comuns, necessidades e desejos" (Hardt, 1996, p.184). Assim "a vontade ética é a vontade que quer o ser" (Misoczky, 2003p. 12).

3 Linstead and Thanem (2007) esclarecem que 0 virtual é abastecido por ideias, mas essas não têm 0 sentido de dar identidade a algo, mas dizem respeito às diferentes tendências por ele incorporadas, capazes de promover a diferenças de si ou atualização, que é sempre uma criação genuína, por nunca refletir exatamente 0 que incorporou. 
de um corpo no interior de uma ordem de encontros (Spinoza, 2009). Com base em Hardt (1996), podemos entender que paixões alegres deleuzianas se referem aos encontros compatíveis e, ao contrário, as paixões tristes dizem respeito aos encontros incompatíveis. Deleuze entende que a possibilidade de um projeto ético tornar-se ativo depende da paixão alegre, que envolve a conveniência de ideias e o consequente aumento da potência de agir, pois ao ser capaz de promover solidariedade política entre corpos, possibilita-se que determinada vontade se estabeleça no corpo social. Ao contrário, a paixão triste envolve a diminuição dessa potência, pois separa a força do que ela pode fazer (Deleuze, 1978, 2002). Dessa forma, o devir ativo e o reativo estão estreitamente ligados ao comportamento de forças qualificadas (Silva, 2014).

Deleuze integra o devir ao conceito de vontade de potência, que considera o elemento genético da força e o princípio de síntese delas, envolvendo a questão qualitativa (ativa ou reativa) que está em afirmar ou negar, sendo esse um princípio determinante da relação entre as forças, pois promove a diferença de quantidade das forças (dominantes e dominadas) (Silva, 2014). Silva esclarece:

\begin{abstract}
Afirmação e negação são qualidades primordiais da vontade, pois afirmar e negar, apreciar e depreciar exprimem vontade, enquanto agir e reagir exprimem força. A afirmação não é ação, mas é a vontade de agir ativa, a vontade afirmativa é o devir ativo. Nilismo é a vontade de potência negativa, vontade de aniquilamento ou devir reativo (Silva, 2014, p.166).
\end{abstract}

Assim, ser ativo ou reativo são qualidades de força e provém da vontade de potência. Deleuze (1976) interpreta a vontade de potência como essencialmente criadora e dotada de qualidades contrárias: afirmação e negação. A mesma se refere a um mundo de intensidades puras, de forças em luta (Machado, 2010; Souza et al., 2006). Para o filósofo, a força reativa (ou vontade negativa) é uma divisão ou subtração da força ativa e se refere ao termo nietzschiano escravo, cujo ponto de vista é dialético e se constitui de uma reação e negação do outro que lhe é exterior. Essa força é uma pulsão bloqueada que, baseada na externalidade, volta-se sobre si por sequer se compreender como força. Ao contrário, a força ativa (ou vontade afirmativa) é uma positividade, expressão pertinente ao termo senhor que advém de uma interpretação imanente e produtiva. O senhor assimila toda resistência como acréscimo de potência e a expande para o exterior (Hardt, 1996; Tórtora, 2008). Desse modo, ideias alegres se baseiam na causalidade eficiente de um movimento imanente e as ideias tristes na causalidade não eficiente de um movimento exterior.

Contudo, quem afirma o ser do devir é o eterno retorno, um ponto crucial da síntese de forças. O eterno retorno sempre produz um devir ativo, o ser no devir, pois é preciso "querer muito" (vontade afirmativa) para que ele retorne (Deleuze, 1976). O devir é diferença, é vontade de potência, deve-se a intensidade do pensamento (Silva, 2014). Assim o pensamento acontece pela síntese de três elementos: eterno retorno, hábito e memória. A síntese do eterno retorno é dinâmica e diz respeito ao ímpeto caótico do poder ser (um princípio de transformação imanente); as outras duas são sínteses estáticas, apenas tornam as coisas identificáveis (Laerke, 2005), pois o hábito provém de relações estruturantes e a memória de relações com o que foi vivido. 
Para Deleuze (1978), a potência do agir é conquistada, pois a formação ética do ser permeia a decisão acerca de determinado modo de vida. Sendo assim, depende-se da seleção de encontros que se faz (questão qualitativa da força, que reverbera na questão quantitativa da relação de forças) e da função prática da memória. Assim, o estatuto de um projeto ético decorre da quantidade e da qualidade das forças envolvidas, podendo tornar-se um projeto político no corpo social, ocasião em que estratégias são traçadas para realizá-lo (Hardt, 1996).

É por meio dessa construção de pensamento que analisamos o agenciamento dos potterheads efetuado por crenças e paixões. As constantes interações entre os fãs no fandom estipulam regras de convivência e normalizações de conduta (Boulaire \& Cova, 2013; Bronwen, 2011; Guschwan, 2012; Lee, 2011, Van Zoonen, 2004) que são levadas para as demais esferas de suas vidas, por se tornarem linhas de subjetivação (Jenkins, 2009). Tal desempenho descortina densas possibilidades de potencializar caminhos analíticos para investigação das práticas de prossumidores utilizando o pensamento deleuziano. A partir daqui as exploramos, ilustrando algumas conexões possíveis.

Por exemplo, Rey (2012) analisa que os usuários das redes sociais buscam voluntariamente as plataformas prioritariamente para produzir, não apenas para consumir, e que os resultados dessa prática beneficiam consumidores e produtores, gerando o valor de uso e valor de troca simultaneamente. Enxergar, primeiramente, a produção e o consumo como linhas de força mutuamente constitutivas certamente potencializa o pensamento para entender como se constrói essa relação; mas, seguindo em Misoczky (2003) e Hardt (1996), a potência de agir é aumentada com a produção de noções comuns, dada ao se favorecer os encontros compatíveis e evitar-se os incompatíveis. Nesse sentido, é possível questionar se, na lógica do capitalismo da informação, consumidores e produtores descobriram-se corpos compatíveis? Como a relação construída entre esses corpos aumenta ou diminui sua potência de agir?

Considerando que para Deleuze e Guattari (2010), o desejo está no campo da imanência, é processo, vem antes do poder, se confunde com as linhas de fuga - sendo determinações sociais primeiras e, à medida em que agencia o campo social, produz os dispositivos de poder, Hardt (1996) analisa que os corpos são constantemente insuflados pelo desejo e que a produção de um evento depende de noções comuns (acumulação e coincidência de desejos, imaginações e poderes) promoverem a transformação de paixões alegres em ações políticas. Para Linstead e Thanem (2007), o rastreio de micropolíticas e práticas revelam a organização de um corpo. Segundo esses autores, tais processos estão sempre em evolução criativa com o virtual exatamente por sua conexão com o desejo. Desse modo, as práticas de prossumidores, sua aproximação com a produção e com a lógica capitalista, podem revelar como o desejo se relaciona e estabelece com a multiplicidade da ordem e da organização que compõem esse corpo. Ainda, podem revelar como o desejo se relaciona com o virtual e com a capacidade de atualização e de que se compõem os fluxos do desejo de prossumidores na era da informação. 
A lógica da abundância (não mais a da escassez) que rege esse modo produtivo representa uma significativa mudança desse cenário (Rey, 2012). Todos os envolvidos se beneficiam da produção e, a princípio, por um tempo ilimitado. O autor identifica que a capacidade de uma produção em provocar novas comunicações seria o seu valor de uso. O olhar centrado em multiplicidades permite questionar se esse seria um valor localizado no potencial afetivo, ou ainda, se esse seria um trabalho realizado em prol de um projeto ético, como tal processo é possível.

Segundo Rey (2012) o papel das instituições perdeu força frente às interações como transmissora de cultura e normalização. Mais enfático, Zajc (2015) afirma que a participação na comunicação se tornou uma necessidade social totalmente dependente da participação de prossumidores. Com os potterheads, pelo seu tempo de permanência, parece manifesto que foi graças aos agenciamentos e seus de processos de subjetivação no fandom que a rede afetiva se manteve ativa, Ihes dando o combustível para seu consumo produtivo. Se os agenciamentos que se dão pautados nessa comunicação são mecanismos de organização (Misoczky, 2003), de que dependem e como eles são construídos? Quais estratégias políticas garantem a continuidade desse fandom?

Outro aspecto é que o conteúdo produzido pelos prossumidores adquirem veracidade e importância a partir de sua própria avaliação, sendo esse mais um fator que afeta profundamente as subjetividades (Zajc, 2015). Reconhecidamente as subjetividades vêm sofrendo profundas transformações (Rolnik, 1995). Mas Almeida (2003) salienta que não existem subjetividades nem objetividades que não sejam operadas por um fluxo criativo pré-individual (traçado no plano virtual). Nesse sentido, analisar de que forma opera (relação virtual-atual), como é composto e como se atualiza o virtual torna-se importante frente à própria indissociabilidade que marca tais mutações sociais (Rolnik, 1995). Considerando que formas subjetivas são provisórias, Almeida (2003) indica a importância de se analisar o agenciamento e o processo ocorrido entre as multiplicidades.

Interessa-nos revelar que saberes estão envolvidos no caso da prática dos potterheads enquanto prossumidores. Para tal, buscamos uma construção exposta aos ajustes da imanência em relação ao devir (Deleuze, 2008), que considera os seguintes aspectos: a produção de subjetividades sofre uma modelação ininterrupta e resultante das múltiplas e intrincadas relações entre saber-poder (Jackson, 2013) e fluxos que Deleuze (2005) transfere para uma relação de natureza. Por outro lado, tem-se, como afirmam Cova e Cova (2012), a rede afetiva que possibilita a existência e permanência de um espaço social e, por fim, assumimos o virtual e o atual como ligados por uma intrincada relação.

Porém, considerando que a relação desses prossumidores acontece no interior de uma sociedade capitalista, a leitura de Nietzsche feita por Deleuze e Guattari (1990; 1997; 2010) propõe uma politização dos modos de criação e produção da vida. Os autores analisam que, no ciclo do processo produtivo, o desejo se estabelece como princípio imanente e que "as máquinas desejantes fazem de nós um organismo" (Deleuze \& Guattari, 2010, p.20). Como o desejo produz o real, todo processo é maquínico e tudo é produção. 
As máquinas desejantes produzem incessantemente e inserem a produção no produto (Deleuze \& Guattari, 2010). Portanto, para os autores não existe esferas independentes entre homem e natureza; as distinções estruturais preconizadas entre a sociedade e seu modo capitalista de produção e consumo apenas fazem supor ao ser capitalista uma falsa consciência de si e dos elementos implicados na relação. Uma vez que as máquinas que operam nos agenciamentos se constituem um plano de consistência e que sua variação contínua forja e perpetua as variáveis de conteúdo e de expressão envolvidos, a sociedade é definida pelas micropolíticas de suas linhas de fuga. Assim, a ação das máquinas nos agenciamentos possibilita a sua definição em desterritorializações, abrindo sempre novos agenciamentos imanentes capazes de constituir devires (Deleuze \& Guattari, 1997).

\section{Drocedimentos Metodológicos}

Apesar do pensamento deleuziano ter embasado nossa construção de pensamento, nosso processo de coleta e nosso olhar dos dados até aqui, estabelecemos como limite dessa investigação levantar de que forma o consumo produtivo dos potterheads se caracteriza em relação à sua vontade potência, ou ainda, desvelar que saberes estão envolvidos nessa construção. Sendo nossa base epistemológica pertinente à corrente crítica pós-estruturalista, optamos por adotar a análise de discurso como procedimento analítico e, dentre os tipos existentes, decidimos pela analítica foucaultiana por sua sintonia de pensamento com a concepção filosófica deleuziana (Deleuze, 2008) e por sua proposta de desvelar exatamente saberes constantemente modelados por poderes.

Tal desafio embasou-se no que é confluente entre os dois pensadores ${ }^{4}$ (Deleuze, 2008), e na possibilidade aberta pela leitura do próprio Deleuze (2005) acerca da formação do saber foucaultiano - a relação visível-enunciável - ao levá-la para uma diferença de natureza. Segundo Hardt (1996), Deleuze o faz transferindo essa relação da esfera epistemológica para a ontológica, avançando na analítica ao desenvolver o conceito da máquina do desejo abstrata e imanente, o que envolve o afeto e a memória como espaços sociais vitais para a dinâmica social (Hardt, 1996).

Seguindo essa linha, nossa análise debruçou-se sobre as práticas dos potterheads, uma vez que essas são capazes de revelar fluxos e dinâmicas dos processos constitutivos dados nas múltiplas e entrelaçadas relações de saber-poder (Almeida, 2003), portanto, manifestando os seus efeitos produtivos (Jackson, 2013). Considerando que o atual é um evento singular que só desfruta de uma existência momentânea, e que os estratos ou saberes são formados em relações de atualização (Linstead \& Thanem, 2007), entendemos que essas envolvem o poder que, operado por meio de saberes, coloca-os em constante metamorfose (Souza, Junquilho, Machado, \& Bianco, 2006). Como afirma Almeida (2003) e explica Linstead e Thanem (2007), todo código comporta uma margem essencial de descodificação, pois no olhar

4 Seguindo Misoczky (2003) abordagens críticas epistemológica e metodologicamente diferentes compartilham princípios entre si. 
deleuziano esses estratos dependem diretamente das operações recíprocas da segmentação molar e molecular. A molar se refere à multiplicidade da ordem externa que opera com base em distinções universalizantes, criando regularidades. A molecular, por sua vez, é de ordem imanente e é dada na interação e contiguidade da auto-organização, estabelecendo uma relação em que as linhas moleculares escapam constantemente dos segmentos molares de organização. Esse vazamento é forçado pela virtualidade e formado por condições ontológicas que precedem, habitam e excedem a organização e a não organização.

Assim, entender que o atual opera e, portanto, potencialmente desvela o virtual (Almeida, 2003), ou melhor, reconhecer que o virtual existe no atual e que o pensamento se move constantemente entre eles, buscamos nesse instantâneo desvelar o feixe de saberes envoltos na vontade de potência dos potterheads. Como diz Souza et al. (2006), é importante tentar explicar a existência e transformações desses saberes a partir da análise de seus porquês, assim seguindo diretrizes da análise de discurso foucaultiana. Entretanto, deve-se buscar também nessa relação a diferença de natureza, em conformidade com a leitura deleuziana da formação do saber (Deleuze, 2005).

\begin{tabular}{ll}
\hline Categorias & Descrição \\
\hline
\end{tabular}

Enunciados

Função enunciativa

Regra de formação

Formação discursiva
Enunciados são a unidade discursiva mais embrionária dessa analítica e se refere a uma forma de existência de determinado conjunto de signos, cujo feixe de relações diz respeito a sujeitos e objetos

As funções dos enunciados assinalam seu desempenho no contexto discursivo, demarcando seus conteúdos e indicando a forma de sua atuação estratégica.

As regras surgem vinculadas às formações discursivas, demarcando as condições e fronteiras da capacidade de fala. As mesmas são formadas por quatro critérios: objetos que tratam do que é apresentado nos enunciados; conceitos que dizem respeito a como noções ganham sentido no contexto discursivo; modalidades caracterizadas pelo modo como os sujeitos falam a partir de certas posições; e estratégias, que indicam como certas ideias, temas e teorias embasam os discursos.

A formação discursiva desvela a regularidade com que os enunciados se relacionam com funções e como as regras os regulam indicando para essas circunstâncias.

Figura 1. Categorias analíticas

Fonte: Adaptado de Foucault (2009)

Segundo Foucault (2009), sua analítica objetiva desvelar a ordem interna a que um discurso está exposto em certo tempo e espaço sociais. Utilizamos o método tendo por base as quatro categorias analíticas fundamentais indicadas pelo autor: enunciados, funções enunciativas, regras de formação e formações discursivas, conforme mostra a Figura 1. Operacionalmente, entretanto, nos guiamos pelo procedimento organizativo de análise adotado por Leão, Camargo e Costa (Camargo \& Leão, 2015a , 2015b; Costa \& Leão, 2012, 2011), consoante à sequência analítica apresentada na Figura 2. 
Etapas do processo

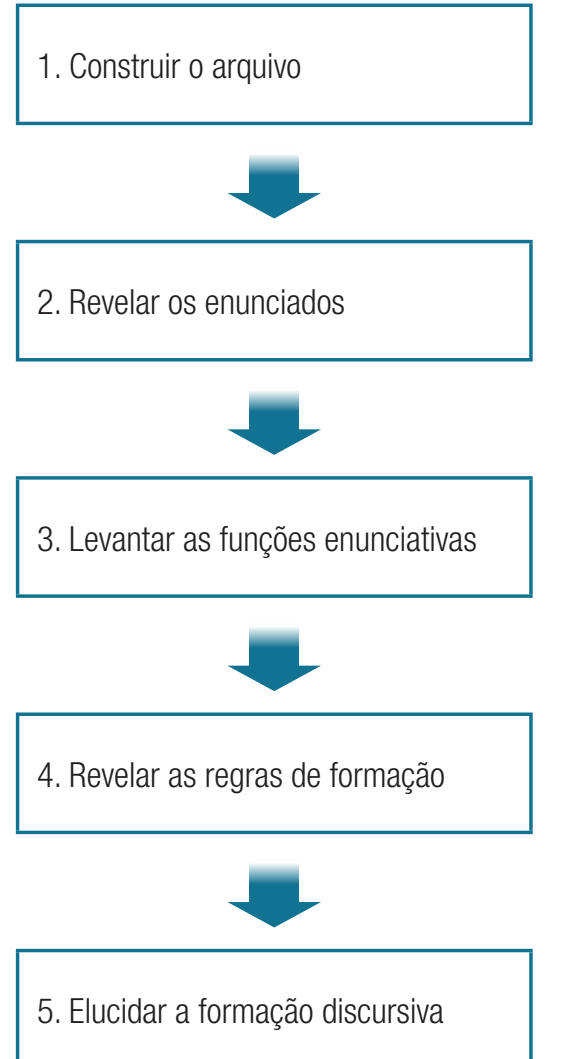

Breve descrição

$\{$ Identificar o conjunto de práticas dos potterheads e coletar documentos constituídos por interação desses fãs nas mídias mais utilizadas por eles.

$\{$ Identificar em meio às práticas os enunciados, verificando suas relações síncronas e incidentes.

$\{$ Identificar as funções dos enunciados no contexto discursivo

$\{$ Identificar, a partir das relações entre enunciados e funções, os critérios que estabelecem as regras e revelá-las.

$\{$ Identificar, a partir dos feixes de relações, o sentido que rege o conjunto discursivo

Figura 2. Processo analítico

Fonte: Adaptado de Leão, Camargo e Costa (Camargo \& Leão, 2015ª, 2015b; Costa \& Leão, 2012, 2011).

Para Foucault (2009), o arquivo comporta o acervo documental cujo conjunto de regras determina o surgimento, a permanência e o desaparecimento de enunciados como acontecimentos singulares e regulares. Sua função, de certo modo, é comparável ao entendimento de um corpus na pesquisa qualitativa (Bauer \& Aarts, 2010). As práticas cotidianas dos potterheads tornaram-se o critério para essa construção, uma vez que para Foucault, as mesmas estruturam discursos no meio social. Desvelamos um total de 21 práticas nesse fandom (Figura 3).

Nosso arquivo foi formado por dados multifocais coletados em mídias sociais, fazendo jus à complexidade do objeto (Flick, 2009). Um total de 593 documentos (280 na língua portuguesa e 313 na inglesa), foram coletados. Do YouTube resgatamos os 67 vídeos e os demais documentos, no total de 526, coletados no formato de texto e imagens, foram originários das plataformas Facebook, Twitter, Tumblr, Instagram, Snapchat, Ask.fm, Yahoo Answer, Share Question, Qzone, Whisper, blogs e websites. A seleção obedeceu a dois critérios: que contivesse a interação entre potterheads e que contemplasse suas práticas cotidianas. 
A coleta fez nossa pesquisa se deparar com algumas limitações - a dinamicidade com que as informações circulam e são excluídas nessas redes, assim como a cultura própria do fandom, a qual os pesquisadores não participam. Para minimizar a primeira condição, tomamos a decisão de coletar nossos dados nas mais variadas plataformas, uma vez que seus conteúdos costumam ser reproduzidos desse modo. Para a segunda, recebemos o amparo consultivo de dois potterheads, que nos ajudaram tanto na validação das práticas cotidianas do fandom como na decisão acerca de quais mídias deveriam ser acessadas.

\footnotetext{
Delatar falsos fãs da saga

Adorar 0 universo Harry Potter

Colecionar merchandises da franquia Harry Potter

Comparar livros e filmes da saga

Depor acerca do universo Harry Potter

Difundir o conteúdo da saga

Participar da seleção de casas tal como os personagens da narrativa

Participar de encontro de fãs de Harry Potter

Participar de estreias de filmes e lançamentos de livros da saga

Reeditar/remixar conteúdos culturais envolvendo a narrativa

Tietar os artistas dos filmes e a autora da saga

Produzir fan fiction baseados na saga

Produzir fan arts baseados na saga

Escrever sobre o universo Harry Potter em meios digitais especializados

Jogar quadribol tal como os personagens da narrativa

Duelar utilizando feitiços tal como os personagens da narrativa

Fazer disputas para ver quem tem mais conhecimento da saga

Degustar feijõezinhos tal como os personagens da narrativa

Fazer tatuagens de símbolos do universo Harry Potter

Fazer cosplay de personagens da saga

Rever filmes e reler livros da saga
}

Figura 3. Práticas de potterheads

Nosso processo buscou atender aos critérios de qualidade da pesquisa qualitativa (Paiva, Leão, \& Mello, 2011). A diversidade de dizeres coletados nas mídias propiciou a riqueza de informações em relação ao objeto pesquisado, atendendo a noção de representatividade do corpus de pesquisa. Os constantes questionamentos efetuados no processo analítico acerca das relações entre evidências empíricas e o corpo teórico contemplaram o critério de reflexividade. A validação da análise efetuada pelo segundo autor contemplou o critério de triangulação dos dados. Por fim, respeitando os limites estipulados para apresentação da pesquisa, buscamos observar o critério de descrição rica e detalhada da pesquisa. 


\section{Descrição dos Resultados}

Nossa análise revelou uma formação discursiva sustentada por um feixe de relações composto de dezesseis enunciados, onze funções e duas regras de formação, cujos elementos e relações são apresentados na Figura 4. A formação discursiva revelada em nosso campo trata da importância da vontade de potência para continuidade do próprio fandom.

Os enunciados foram nomeados por meio de proposições afirmativas, no intuito de clarificar seu sentido no cenário discursivo. Para nominar as funções enunciativas empregamos verbos no infinitivo, esclarecendo a sua ação sobre os enunciados. Para esclarecer os critérios de regras, lançamos mão de substantivos para apresentar objetos, bem como de conceitos, modalidades e locuções substantivas para denominar as estratégias. Para apresentar as regras utilizamos uma estrutura de oração simples e explicativa em seu sentido no contexto discursivo.

As regras foram formadas por: dois objetos (vínculo social - 01 e alteridade - O2), por dois conceitos (ressonância - C1 e dissonância - C2), por uma modalidade (ética - M) e por duas estratégias (princípio moral - E1 e diferença do outro - E2).

A regra denominada $\mathbf{A}$ conveniência das ideias se afirma como alegria foi composta por $01, \mathrm{C} 1, \mathrm{M}$ e E1. A regra chamada de A inconveniência de ideias se afirma como tristeza foi formada por O2, C2, M e E2. Quanto aos enunciados, duas formas de relação se apresentaram entre eles: as síncronas, em que os mesmos se amparam e se explicam mutuamente (representadas por linhas nos enunciados da Figura 4); e incidentes, em que um enunciado elucida o outro (representados por setas, no mesmo espaço). Tais relações indicaram a existência de dois grupos de significação referentes aos feixes de relações formadores das regras: um que evidenciou as afinidades que foram exaltadas e constantemente trabalhadas pelos potterheads e outro que ressaltou 0 processo de estabelecimento de alteridade desses fãs. 


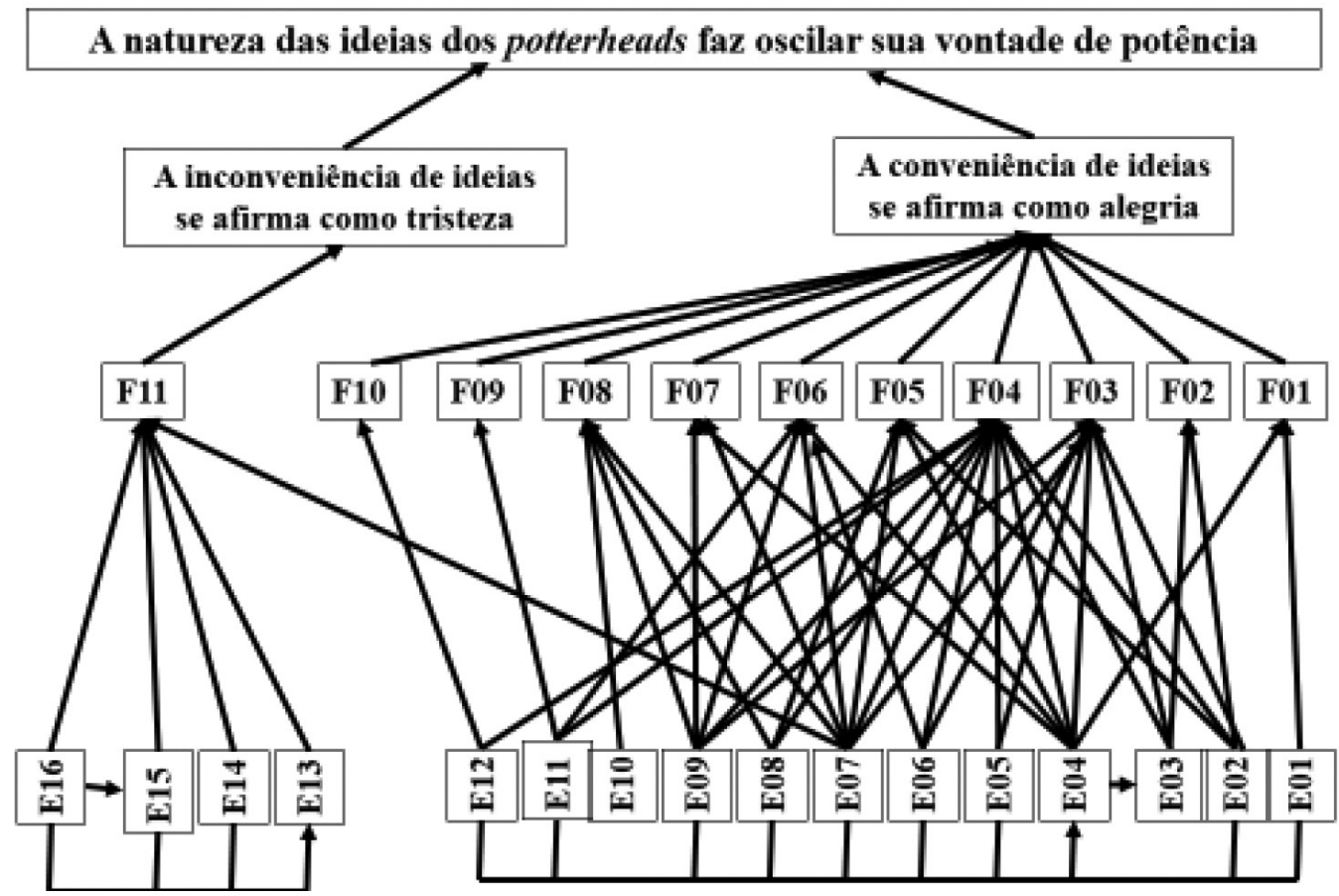

Enunciados

\begin{tabular}{|l|l|l|l|}
\hline E01 & Potterheads se precaveram em relação à lei de direitos autorais & E09 & Potterheads cultuam o cânone \\
\hline E02 & Potterheads se identificam com a saga cinematográfica & E10 & Potterheads não resistem as práticas do fandom \\
\hline E03 & Potterheads estabelecem vínculos no fandom & E11 & Potterheads são nostálgicos em relação ao universo \\
\hline E04 & $\begin{array}{l}\text { Potterheads estabelecem identificações com integrantes do } \\
\text { fandom }\end{array}$ & E12 & Potterheads expressam gratidão ao cânone \\
\hline E05 & Potterheads marcam o corpo com símbolos do universo & E13 & Potterheads estabelecem alteridade \\
\hline E06 & Potterheads se identificam com o cânone & E14 & $\begin{array}{l}\text { Potterheads são atestados pelo domínio de saberes do } \\
\text { universo }\end{array}$ \\
\hline E07 & Potterheads produzem cultura a partir do universo & E15 & Potterheads fundamentam sua condição de fã \\
\hline E08 & Potterheads colecionam itens relacionados à saga & E16 & Potterheads ressentem-se do preconceito social \\
\hline
\end{tabular}

Funções

\begin{tabular}{|l|l|l|l|}
\hline F01 & Resguardar condição de produtor & F07 & Enaltecer o cânone \\
\hline F02 & Atenuar estigmas sociais & F08 & Satisfazer vontade de práticas do fandom \\
\hline F03 & Evidenciar empatia entre membros do fandom & F09 & Preservar a segurança do cânone \\
\hline F04 & Nutrir vínculos no fandom & F10 & Reconhecer benefícios da relação com o cânone \\
\cline { 1 - 2 } F05 & Valorar o universo Harry Potter & \\
\cline { 1 - 2 } F06 & Prover condição de fã & F11 & Demarcar identidade \\
\hline
\end{tabular}

Figura 4. Mapa das relações da formação discursiva

Passamos a expor os resultados a partir das regras de formação, tratando de cada um dos feixes de relação e ilustrando o procedimento analítico por meio da inserção de dados do arquivo. 
A regra que apresentou um número maior relações entre saberes e funções foi a conveniência das ideias que se afirmam como alegria. Essas ideias se apresentaram por meio das relações entre os 12 enunciados e suas 10 funções no contexto discursivo. Os enunciados tratam de saberes cujos princípios e identificações são compartilhados e cultuados por constituírem o próprio modo de ser potterhead, ou seja, eles carregam em si a causalidade eficiente de um movimento imanente. As funções dizem respeito às finalidades que envolvem a manutenção desse modo de vida. Desse modo, a conveniência das ideias se apresentou de diversas formas, mas foi devido à sua intensidade, por sua vez, relativa à qualidade e quantidade de força afetiva envolvida, que a potência do agir foi conquistada ao mesmo tempo que estabeleceu o que é querido (o estatuto de um projeto ético). Quando praticado, esse tomou a forma de um projeto político, despertando solidariedade entre os corpos, como elucidou Hardt (1996).

As relações entre enunciados desse feixe apontam como isso acontece, pois o enunciado que trata dos vínculos estabelecido no fandom (E3) revelou-se proveniente (relação incidente) do enunciado que diz respeito ao estabelecimento de identificações entre os integrantes desse espaço social (E4). Esse, por sua vez, foi derivado (relação incidente) de uma relação entre si (relações síncronas) de quase todos os demais enunciados desse feixe de relações. Dentre os critérios reveladores dessa regra, o vínculo social (O1) foi o objeto por meio do qual se promoveram a ressonância das ideias, sentimentos e modos de atuação comuns. Os potterheads se revelaram persuasivos, sendo essa a qualidade que manteve o ethos da coletividade. Isso elucida o motivo da função que se refere ao estabelecimento de laços morais por meio de vínculos (FO4) ter se mantido como finalidade de grande número de enunciados nesse feixe. Outras três funções também se revelaram expressivas: uma se referindo às manifestações de empatia entre fãs (F03), outra evidenciando o apreço comum de fãs ao universo Harry Potter (F05) e, por fim, outra se referindo à vontade dos fãs de participar das práticas do fandom (F08). A Figura 5 elucida a questão da empatia.

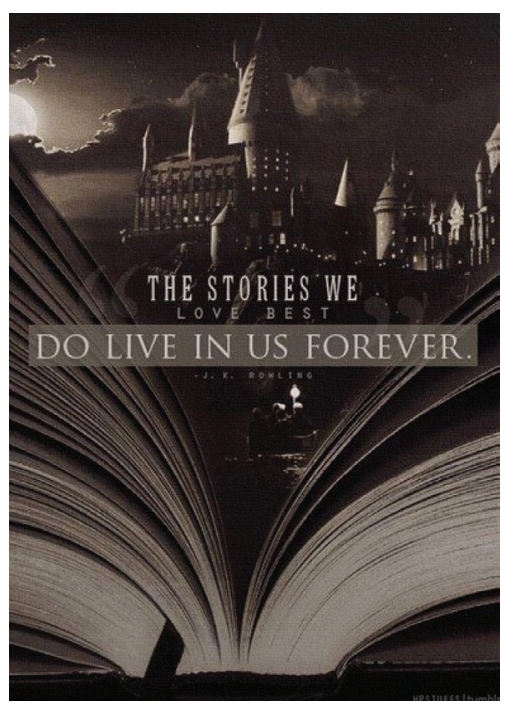

Figura 5. A história que vive em nós para sempre

Fonte:Tumblr.com (Imagem publicada em https://nl.pinterest.com/pin/16888567326904469/?|p=true, coletada em 15/02/2019). 
Ao demonstrar empatia, o fã evidencia o quanto é capaz de compreender emocionalmente o outro, ao se colocar em seu lugar por possuir afinidades e, por meio delas, descobrir/construir um gosto em comum, sentimentos semelhantes (tais como amor, tristeza, saudade, admiração, reconhecimento) e vontades análogas como a de perpetuar sua ligação com o cânone. A análise revelou que o projeto ético dos potterheads foi traçado a partir da vontade de perpetuar sua relação com o universo. Muito envolvidos, os fãs acreditam que ser potterhead é um "estilo de vida" e não desejam se desvincular dessa ligação afetiva, trabalhando incessantemente para manter viva o que consideram a "cultura Potter". Isso evidencia como o acúmulo e a justaposição de desejos, imaginações e poderes, produz noções comuns capazes de transformarem paixões alegres em ações, aumentando a potência de agir (Hardt, 1996; Misoczky, 2003).

A vontade de perpetuar a condição de ser potterhead foi muito evidenciada no anúncio do último filme, ocasião em que as imagens promocionais do seu anúncio tinham por título a expressão: "it all ends". Após mais de uma década de convivência, a frase provocou uma enorme comoção entre os potterheads, os quais, em resposta, criaram bordões como: "will never be end" (sic), movimentando o fandom. A proporção com que isso aconteceu despertou o interesse de estudiosos como Inocêncio, Cavalcanti e Izidio (2014), que analisaram esse efeito. No blog da Evanston Public Library, no dia 21 de junho de 2011, uma fã fez o seguinte comentário acerca do cartaz: "But for diehard HP fans (and yours truly here may be among the oldest), it will never end". O texto lembrava os fãs de que a existência de uma infinidade de produtos e livros "viciantes" continuariam sempre disponíveis para as comunidades (texto publicado em https:// evanstonpubliclibrary.wordpress.com/2011/06/21/it-all-ends-7-15/, coletado em 10/09/2016).

Contudo, essa vontade manifestou-se fortemente por meio de uma palavra: "always", que surgiu embasada na narrativa e indica o significado da lealdade e do amor verdadeiro. Essa palavra se transformou no lema desses fãs, transferindo tal significação para sua relação com o cânone. $\mathrm{Na}$ cultura globalizada em que se encontram inseridos, o termo foi utilizado na língua inglesa e constituiu-se o símbolo por excelência do fandom, sendo marcado com orgulho na pele (Fig.6) e nos objetos dos potterheads, o que denota a promessa de manter um vínculo eterno ao cânone, simultaneamente indicando o valor desse universo para suas vidas. O pensamento tornou-se uma espécie de norteador moral dessa cultura, nutrindo as ideias pelas quais se trabalha com afinco no fandom. Podemos entender que esse tornou-se um projeto ético definido em torno de uma ideia estabelecida nesse corpo: sua continuidade. Ético, pois seguindo Rolnik (1995), esses fãs se deixaram afetar por essas forças (relativas à sua capacidade), assumiram uma posição frente à essa relação (deliberando suas virtudes) e nelas afirmaram uma diferença, produzindo-se a partir de uma vontade afirmativa, como analisa Machado (2011). É um projeto, pois foi construído na noção comum (arranjo político) pautada numa vontade, considerando que "a vontade ética é a vontade que quer o ser" (Misoczky, 2003, p. 12). As Figuras 5 e 6 ilustram essa relação. 


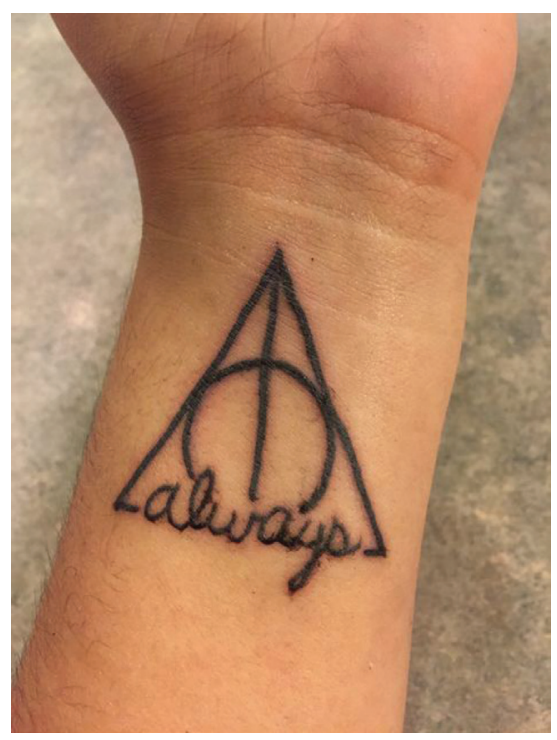

Figura 6. Para sempre!

Fonte: Pinterest.com (Imagem publicada em: https://br.pinterest.com/pin/520728775647284051, coletada em 10/08/2017).

Postagens que expressam a força desse vínculo e a jura de seu amor eterno são um tipo de produção de fã recorrentemente veiculado nas redes sociais. Esse tipo de produção se espalha rapidamente, recebendo inúmeras curtidas e comentários, evidenciando um dos modos como a vontade de continuidade se afirma e se dissemina. Os casos ilustram a recursiva jura de amor eterno ao cânone, sendo parte das práticas de culto ao cânone (E09) que tem por função exaltar a importância dele (F07), ao mesmo tempo provendo a condição de fã (F06). O trabalho para manter viva a "cultura Potter" tornou-se uma intensidade, pois se estabeleceu por meio de ideias adequadas, permitiu que o afeto funcionasse como uma cola nas relações subjetivantes. O pensamento aumentou a potência do agir por promover solidariedade política entre corpos, permitindo à vontade de continuidade voltar sempre e se disseminar no corpo social (Deleuze, 1978, 2002). A vontade de potência tornou-se positividade, pois a jura é parte de uma construção memória-tempo, refere-se a uma ética e deve-se a um trabalho que propicia a atualização do virtual, frente às novas forças que se estabelecem no tempo. O ser querido sempre volta, embora a vontade de potência seja afetada pela síntese do tempo, pois o eterno retorno é um ato de afirmação dessa vontade (Misoczky, 2004). Dada no plano de imanência, essa construção ocorreu pelas três repetições que estabelecem a síntese do pensamento: o hábito, a memória e o eterno retorno (Laerke, 2005). O culto ao cânone foi estabelecido como uma ordem, ou seja, a prática de reafirmar seu compromisso com o cânone aconteceu como um hábito alimentado pela memória. O eterno retorno da vontade decorreu da intensidade ou ímpeto do "poder ser" esboçado pela vontade e/ou compromisso com o cânone. Assim, apesar dessa vontade imanente ser abastecida por uma multiplicidade de práticas (essa sendo uma delas) também sujeitas às atualizações do tempo, eticamente ela permaneceu a mesma - a vontade do que quer o ser. O caso ilustra como a produção afetiva do prossumidor 
promove o interesse no consumo do produto, retém o cliente e constrói valor para a marca. Contudo, o que antes podia ser controlado pela produção, agora acontece em conformidade com os quereres de seus consumidores.

Enquanto comunidade cultural, os potterheads afirmam gostar dos mesmos assuntos, fazer as mesmas coisas e se conduzir e apoiar do mesmo modo, conforme ilustra o trecho de fala a seguir:

\begin{abstract}
A gente vai pro cinema, a gente assiste os filmes, a gente interpreta, a gente age como eles, a gente gesticula como eles, como os personagens, a gente fala como, anda como. [...] é um caso de amor com o livro, segundo com a autora e terceiro com os fãs. (Trecho de texto publicado em https://www.youtube.com/watch?v=385BlxZqnLA, coletado em 07/10/2014).
\end{abstract}

Esse exemplo é parte de respostas dadas a uma entrevista ocorrida durante o lançamento do último filme, em que o entrevistador busca saber como esses fãs vivem o mundo de Harry Potter. As respostas revelam que E04 tem por funções F04. F05 e F07. O vínculo com o cânone lhes foi o meio de estabelecer paixões alegres, pois dessa fonte imaginativa, os potterheads selecionaram encontros convenientes e partilharam ideias adequadas construindo valores imanentes. A construção da noção comum deve-se ao poder de ser afetado e a potência de compreender desse corpo (para Deleuze, um esforço de pensamento), pois a imaginação só pode ser operada por meio dela (Hardt, 1996). Desse modo, eles ativam o mecanismo e transformam a ideia em razão de "um caso de amor" que se tornou uma forma de vida desejada (um projeto ético) que vale a pena manter. Assim, a vontade de continuidade se estabeleceu como atividade imanente e produtiva. Como o pensamento ético impõe à vontade a rigorosa regra do eterno retorno, ele sempre volta sendo esse "[...] o centro da gravidade mais sólido" (Deleuze, 1976, p.35). As diversas formas de identificação entre membros no fandom promovem encontros convenientes e geram intensidades, além de criar laços morais entre potterheads. Essas intensidades compõem a natureza dos potterheads pois, como diz Deleuze (2002), intensidades propiciam a potência do corpo por meio de ideias que se afirmam como alegria. Compartir pensamentos construídos por meio dos signos do universo dá ao afeto as ideias para que se efetue, promovendo a cola entre os potterheads. Desse modo, eles defendem com vigor as verdades e os valores que produzem nesse meio. Num contexto em que o papel das instituições perdeu força frente às interações como transmissoras de cultura e normalização (Zajc, 2015), os prossumidores são proativos (Ritzer, 2015a). Em seu constante trabalho de produção de conteúdo e valor (Cova \& Cova, 2012; Rey, 2012; Ritzer, 2015a), os potterheads traçaram seus códigos morais de convivência e, como afirma Machado (2011), são seus próprios legisladores, uma vez que a veracidade e importância do conteúdo que produzem depende apenas de sua análise.

Outro exemplo de como se estabelecem ideias adequadas pode estar no apoio mútuo frente aos estigmas sociais que os vitimiza. Considerando que fazer cosplay é uma prática usual desse fandom, e que os fãs tornaram-se adultos ao final dos lançamentos da saga, um dos estigmas que frequentemente os atormenta é o fato de serem cobrados como adultos que gostam de coisas de criança, como no trecho de fala: "Minha família quer que eu pare de fazer cosplay, pois dizem que estou ficando velha pra isso... Tenho 17 anos! y-y". A fã mantém um perfil no Facebook visando tratar dos 
"sofrimentos da vida de um cosplay". No trecho de fala a seguir mostramos alguns dos muitos comentários solidários postados:

\footnotetext{
Lembra a eles que cosplay é coisa de adulto, criança não sabe costurar e fazer acessórios. Vish, dá pra eles o exemplo do meu pai, ele é cosplayer e já ganhou uns desfiles.

Sinceramente, se são seus pais que pagam por seus cosplays, espere poder pagar você mesma por eles para que você possa sozinha decidir se vai continuar ou não. Desculpe a sinceridade. Eu comecei em 2002 já adulta.

(Trechos de textos publicados em https://www.facebook.com/Cosplayer Depressivo/posts/ 276774869142435?stream_ref=5, coletados em 17/11/2014).
}

O cosplay, apesar de ser um "hobby" cada vez mais comum no cotidiano de fãs, ainda é alvo de pressões para os potterheads, tal como é a sua ligação de amor com o cânone; professores, conhecidos e principalmente a própria família entendem que esses fãs estão se dedicando a brincadeiras que não cabem mais à sua idade e assim deixam de lado coisas consideradas "mais sérias" como estudo e trabalho. Essa, entre outras, são linhas de força trazidas pelo tempo, afetam a vontade de potência e o seu 'querer-vir-a-ser-mais-forte', intensificando a luta entre forças. Tais variações intensivas conduzem à diferença (DeLanda, 2006), pois é capaz de arrastar o ser e os fazer devir outro (Rolnik, 1995). Como ser estigmatizado é algo comum aos potterheads, a solidariedade entre eles se estabelece e um apoio encorajador é construído em forma de argumentos que se tornam lógicos e mais fortes, estabelecendo vínculos no fandom (E03) que visam amenizar a pressão causada por tais marcas sociais (FO2). O apoio solidário objetiva manter viva as práticas do fandom e legitimar a "cultura Potter", fortalecendo e ao mesmo tempo transformando sua potência de existir.

A prática do cosplay possibilita ao fã a troca de conhecimentos para enfrentar as pressões do mundo e o apoio à sua condição, consolidando a vontade de não quebrar esse vínculo. A partir da noção comum, o afeto foi a cola para as relações subjetivantes e as ideias intensificaram a vontade de potência (Deleuze, 1978, 2002). Por isso, estando juntos a vontade, o apoio/ segurança, a emoção e o incentivo, tanto esse como outros hábitos do fandom tornam-se irresistíveis, sendo por isso que E10 tem por função F08.

Os concursos de cosplayexistem no mundo todo, sediados principalmente nos grandes encontros para celebrar o "universo geek". A Figura 7 ilustra essa prática. O exemplo traz a imagem de uma criança fazendo cosplay de Harry Potter, acompanhada de um cachorro com três cabeças, em referência ao animal da narrativa de nome Fluffy. Com a prática, a narrativa é revivida, a cultura é mantida, estimula-se a vontade de participar desses encontros e se abastece a condição de ser potterhead. Portanto, fica evidente como acontece a produção de cultura (E07) visando satisfazer vontade (F08) e fortalecer a condição de fã (F06). A prática promove intensidades e essa força afetiva propicia a continuidade da condição de fã, pois, na medida em que as vontades atravessam o corpo social, os membros percebem/ constroem suas afinidades, identificam dificuldades comuns e se apoiam mutuamente para vencê-las. Tudo isso contribuir para o estabelecimento de um entendimento de como deve ser a vida, estreitando os laços com o universo. Assim, tecer noções comuns promove ideias convenientes, pois 
elas se afirmam no corpo dos potterheads e fazem aumentar sua vontade de potência, aproximando a força afetiva do que ele pode fazer.

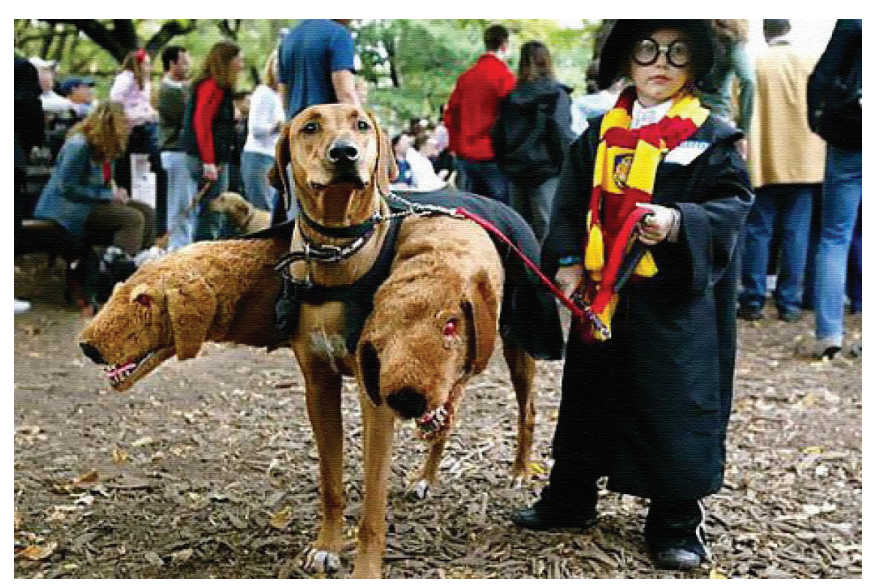

Figura 7. Harry Potter and the Cosplay of Geekery

Fonte: Wordpress (Imagem publicada em https://hegeekshegeek.wordpress.com/2011/07/14/harrypotter-and-the-cosplay-of-geekery/, coletada em 13/11/2014).

A segunda regra revelada em nosso arquivo, A inconveniência das ideias se afirma como tristeza, indica como os potterheads recorrentemente ressaltam suas características pautados nos atributos presentes em não-fãs. Tais atributos, pautados em características da externalidade, promovem o que Deleuze entende por movimento negativo, condição que só produz resultados abstratos (Hardt, 1996). Para Deleuze (1976, p.31) essa seria uma vontade reativa, pois sendo a vontade de potência dotada de duas qualidades contrárias (afirmação e negação), "ativo e reativo são qualidades de força que decorrem" dela.

Assim, ideias tristes surgiram no processo de estabelecimento da alteridade, pautadas na causalidade não eficiente de um movimento externo. A condição de potência dos potterheads baseada na alteridade não é capaz de produzir solidariedade política, pois constituiu-se uma força refreada, fazendo oscilar para o mínimo a vontade de potência dos potterheads. As relações entre enunciados apontam como necessidade dos potterheads em fundamentar sua condição de fã (E15) e estabeleceu-se como a consequência (relação incidente) do ressentimento que eles sofrem com os preconceitos sociais (E16). A relação síncrona dada entre E16, E16 e E14 (quando esses fãs são atestados pelo domínio de saberes) incidem diretamente no estabelecimento de alteridade (E13).

Utilizando a diferença externa e não um atributo imanente para demarcar suas características, os potterheads selecionaram ideias não convenientes, que, portanto, não conseguem abastecer o afeto, não promovem a solidariedade política e nem abrem a condição para que surja ou se alimente uma vontade. Esse tipo de ideia jamais atinge suas últimas consequências como potência, pois para Deleuze (1974) a vontade de potência manifesta-se primeiro como o poder de ser afetado a partir da presença do que lhe é assimilável. É parte do conhecer e do querer. Por não ser imanente, não estabelece o querer capaz de propiciar a síntese do eterno retorno, que é o formador do pensamento ético e seletivo. 
Em um vídeo-paródia, dois fãs caracterizados com elementos de da saga (Fig.8) intentam resinificar a negatividade da acusação de fanatismo recorrentemente atribuídas aos fãs de Harry Potter, comparando-os aos fãs de futebol (ver trecho abaixo da Fig. 8). Um está com óculos semelhantes ao usado por Harry Potter e ambos carregam em sua testa um raio, em referência a cicatriz do personagem.

A ideia da comparação é demonstrar que ser fã é algo comum no meio social, porém ser fã de futebol é um tipo de fanatismo capaz de prejudicar outras pessoas. Ser fã de Harry Potter, por outro lado, não prejudica a ninguém. Assim, por meio de um argumento construído com o que lhes é externo, eles tentam diminuir o peso da acusação que os caracteriza como um dos mais "chatos" tipos de fãs que existe. A acusação de fanatismo recai sobre eles exatamente devido à peculiaridade das características que lhes são pertinentes, tais como dedicação, amor e forte vínculo com o universo. Desse modo, esses fãs produzem cultura (E07), reagem ao julgamento (E16), estabelecem alteridade (E13) e respaldam sua condição de fã (E15), objetivando demarcar sua identidade (F11). Aqui, entretanto, o afeto não encontra uma ideia adequada, pois a característica de "ser" (não violento e, portanto, não danoso) depende da possibilidade violenta que é do outro. Esse tipo de estratégia diverte, mas não é capaz de incitar a solidariedade política, pois para Deleuze (1976) esse é o ponto de vista do escravo, sua qualidade de força é reativa, portanto uma subtração da força ativa, que se volta sobre si (não se expande) ao não se compreender como força.

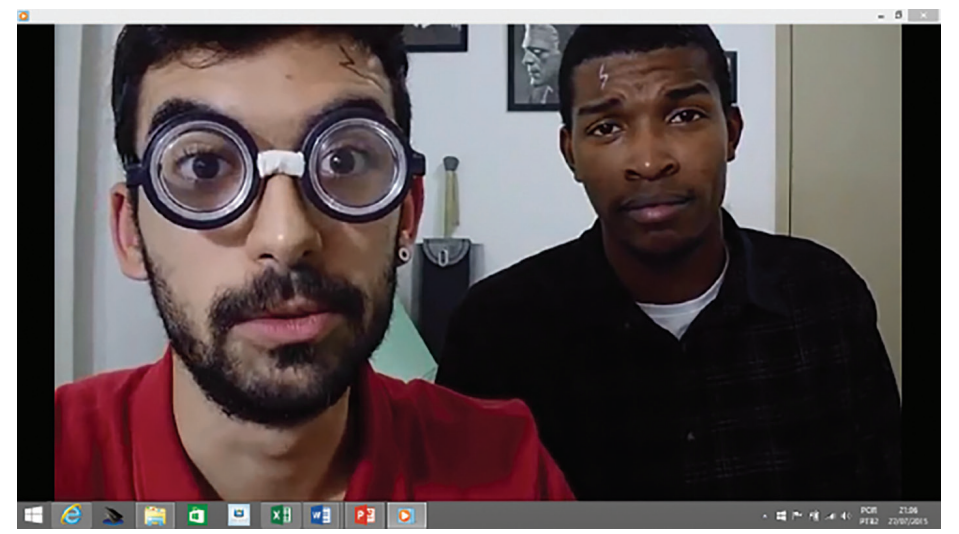

Trecho de diálogo presente no vídeo:

- A gente não tá falando que é ruim, entendeu? A gente só está dizendo que qualquer tipo de fanatismo, seja ele político, religioso ou mágico, faz mal à saúde! - O principal fanatismo que vocês já repararam é sobre Harry Potter.

[...]

- Tem muitos modos de fanatismo que podem prejudicar muito a vida de muita gente.

- Corroer o seu cérebro, tipo, o futebol...

- E infelizmente, principalmente com o futebol, a gente vê muito vandalismo, muita briga, muita coisa ruim...

- Às vezes você não sabe nem porquê você tá brigando, mas, tipo, você tá no meio e não tem o que fazer.

- ... ou às vezes você tá brigando, é um idiota, então espero que você se lasque, se for um idiota desses ... você leva uma e não sabe nem da onde tá vindo!

Figura 8. Fanatismo por Harry Potter

Fonte: Youtube (Vídeo publicado em https://www.youtube.com/ watch?v= eKinAXFpXn0, coletado em 07/10/2014). 
O mesmo acontece quando para demarcar identidade (F11), os potterheads estabelecem alteridade (E13) quando são afirmados por meio do domínio de saberes desse universo (E14). Uma das características mais fortes desses fãs é o domínio dos saberes do universo. Contudo, eles empregam essa qualidade para demarcar os falsos fãs, ou seja, a utilizam para acusar os posers - os que se dizem fãs, mas não possuem tal competência. No fandom, o fã considerado verdadeiro é aquele que dedica muito tempo e muito esforço para dominar tais saberes. Por essa razão, querer se passar por fã desfaz a importância desse empenho. Da mesma forma, quando produzem cultura (E07) denotam que nenhum poser "é legal" e colocam suas vontades, sentimentos e conhecimentos em termos negativos.

Dessa forma, uma característica forte e definidora dos potterheads (dedicação e domínio do conhecimento da saga) torna-se uma ideia inadequada, pois tomados pelas acusações de que são repetidamente vítimas ("chatos", "fanáticos"), justificam sua condição demarcando sua identidade pela alteridade. Em outras palavras, dentre a multiplicidade de forças e tendências heterogêneas que precederam, habitaram e excederam a organização desse corpo (Linstead \& Thanem, 2007), nessa existência momentânea da formação do virtual, prevaleceu uma diferença de ordem, desqualificando a força de uma diferença embasada no tempo experimentado. Os conteúdos gerados pouco agregam valor aos produtos uma vez que, diretamente, não trataram de suas qualidades, e seu pouco apelo afetivo sequer garantiu uma audiência representativa, como visto nas postagens pautadas em paixões alegres.

\section{Considerações finais}

Nossa investigação se propôs a revelar como o consumo produtivo dos potterheads se caracteriza em relação à sua vontade potência. A partir de suas práticas identificamos uma formação discursiva referente a como a vontade de potência desse corpo oscila de acordo com a natureza de suas ideias. Essa vontade de potência é aumentada à medida que o estabelecimento de vínculos, as identificações, os hábitos e as condutas assumem funções relevantes, capazes de nutrir ideias convenientes, possibilitando a ação da força afetiva. É, ao contrário, diminuída, quando os potterheads buscam na determinação externa os subsídios para demarcar sua identidade, sendo essas as duas regras de formação reveladas.

Podemos dizer que os encontros alegres foram uma produção da racionalidade de condutas instauradas nessa cultura, que transformou o que era imaginação em razão, trabalhando em favor do agenciamento de suas vontades. A vontade imanente de manter-se vinculada ao cânone surgiu como uma construção ética que foi traçada no tempo de memória e que o tempo de memória antecedeu ao ser, mas o tempo linear se revelou quando praticada. A vontade de potência foi construída na síntese das forças quantitativas e qualitativas. Essa força, por constituir-se um querer imanente (a vontade do ser querido), implicou em uma estratégia política que recorrentemente volta a ser praticada, pois tudo que se quer muito, se quer também seu eterno retorno e a diferença produtiva de natureza que 
esse promove, o que garante uma adequação contextual e a continuidade de existência.

Por outro lado, ao demarcarem sua identidade por alteridade, promoveram uma diferença de grau e minimizaram essa vontade, pois dos encontros deles não extraíram ideias adequadas para que a força afetiva pudesse se instaurar. Vale ressaltar que, embora demarcar identidade pela alteridade seja uma coisa comum aos potterheads e, inclusive, existam perfis na rede que se voltem especificamente para esse trabalho, se analisarmos em termos das relações do conjunto de forças, eles promoveram para si mais encontros alegres do que tristes. Se não fosse assim, essa forma de vida não teria resistido ao término da saga cinematográfica que coincidiu com a passagem dos fãs para vida adulta, que é certamente a condição de onde resulta a maior parte das críticas as quais os fãs são vítimas. Notamos também que dominar os saberes do cânone, uma qualidade determinante desse fã, também não foi uma ideia reconhecida como força (questão de conhecimento), não sendo capaz de abastecer sua vontade de potência.

Concluímos que os potterheads mantiveram sua vitalidade por meio de um trabalho qualitativo: eles traçaram no espaço temporal da memória uma vontade de potência - a vontade de continuidade - e trabalharam no espaço relacional do afeto o modo de efetivá-la. Aqui os potterheads operaram de modo hábil sua vontade de potência e o eterno retorno efetuou-se por uma multiplicidade de práticas (entre saberes e quereres), mas também pela mesma vontade imanente de continuidade, o que promoveu encontros alegres e produziu noções comuns, criando ideias adequadas que recorrentemente abasteceram a força afetiva, mantendo, assim, sua vitalidade.

Enquanto prossumidores, os fãs elucidaram como acontece o processo de consumo produtivo. Ponderamos que, tendo a internet como plataforma de interação pela velocidade e extensão com que disseminam as informações, tornou-se muito mais difícil gerenciar os valores e princípios que estão sendo agregados a uma marca, ou atribuídos a um serviço. As novas condições de tempo e espaço também trazem dificuldades para os pesquisadores. Apesar de divulgar a marca e demarcar condutas do fandom, a limitação da potencialidade de afetar e ser afetado causada pelos afetos passivos nos pareceu também limitador nos trabalhos da prossumerização. Contudo, enxergar o processo de produção e consumo como um continuum possibilitou o entendimento de como ele se estabeleceu. A cultura própria do fandom, construída em torno dos signos do cânone, determinou a conformação de condutas, de crenças e de valores, estabeleceu o hábito de rotinas e alimentou a memória. Esse sistema possibilitou as identificações com as ideias capazes de instaurar as forças afetivas nesse espaço, sendo capazes de estabelecer um projeto ético, cuja ação política promove a manutenção da potência de existir. Acreditamos que é possível aproximar o modus operandi do fã ao de prossumidores de marcas imersos na cultura de suas comunidades, por exemplo.

O pensamento da multiplicidade permitiu enxergar como uma lógica que é do mercado e sua estreita relação com o meio social, bem como as novas formas de sociabilidades e de agenciamentos daí gerados são partes de sistemas complexos, abertos e mutuamente constitutivos. Assim, dentro de um contexto de novas condições de vida interligadas pela tecnologia em que 
instituições tradicionalmente norteadoras da vida estão perdendo sua força, vemos surgir consumidores produtivos que constituem identidades e novos modos de subjetivação ao criarem para si modos de vida estruturados em torno das significações oriundas de cânones da indústria do entretenimento. Analisar a vontade de potência desse modo de vida revelou como o processo se estabeleceu e pôde ser perpetuado. Seguindo Nietzsche (2011), o querer da intensificação mostrou-se próprio à vida e foi dado pela vontade poder e pelo eterno retorno da vontade pautados na afirmação. Como um organismo e por princípios imanentes, os potterheads e sua rede afetiva se vincularam aos produtos e aos seus modos de produção capitalistas em conformidade com o pensamento de Deleuze \& Guattari (2010). O trabalho desses prossumidores adotou estratégias próprias à lógica do mercado e por querer a continuidade de sua condição, divulgou e manteve o interesse de consumo nos produtos.

A produção da vida (o ser Potterhead) efetuada por meio do consumo, aponta como o prossumidor atua e se beneficia de sua cocriação social devalor, a qual é pautada nos signos de um produto da indústria do entretenimento. Logo, ao fazer perpetuar o valor social dessa ideia, seu trabalho tornou-se bastante lucrativo, até mesmo vital para a força da franquia, que estendeu sua linha de produtos aumentando a satisfação, a retenção do cliente e o próprio o valor da marca, como tem acontecido nesse mercado. Assim, o valor de uso de uma ideia adequada estaria na potencialidade com que uma postagem provoca visualizações, identificações e grande disseminação fortalecedora da condição de ser. Logo, as paixões alegres aumentaram a potência de agir, potencializando o afetar e o ser afetado (Deleuze, 1978, 2002) dos potterheads e, portanto, o fandom garantiu sua longevidade e cumpriu sua função social de orientador moral e estruturante, ao mesmo tempo que beneficiou, estimulou e alimentou a produção da indústria do entretenimento. A relação fortaleceu o organismo pelo imbricamento cada vez maior do desejo e da produção da vida com a racionalidade capitalista. Novas subjetividades estão sendo constituídas nesse tipo de relação virtual-atual em que se estabeleceu tal ciclo do desejo e suas sínteses produtivas, como afirma Rolnik (1995). Certamente, desterritorializações abriram frestas para novos devires em andamento (Deleuze; Guattari, 1997).

A partir desse pensamento, entendemos que a produção dos potterheads é também a produção de realidades, sendo essas pertinentes ao tempo e espaço que, compartilhados, constituem verdades particulares. Nossa análise dos potterheads enquanto prossumidores revelou como o papel da produção interminável de seus quereres constitui-se uma positividade. Essa se estabelece sempre como uma diferença pura, ou seja, capaz de transformar a natureza de todos os envolvidos, contrariando o discernimento acerca do papel da verdade e do valor como estatutos estáveis. Como os valores capazes de abastecer a força afetiva são imanentes, a produção colaborativa desses prossumidores só acontece se os produtos e serviços cumprirem o papel de constituírem-se ideias adequadas para a ação dos sujeitos. Dependem, portanto, diretamente de sua capacidade de conhecer e de selecionar ideias, ou seja, dependem de sua vontade e da força com que fazem a mesma se estabelecer, afinal, é a imaginação transformada em razão que produz o real como derivação. 
A capacidade dessa prática transformadora dos sujeitos como uma construção intercambiável é muito pouco investigada, bem como a particularidade da atuação dos fãs como prossumidores, apesar de serem reconhecidos como um forte exemplo do processo (Siuda, 2014). Contudo, o presente estudo revela um conhecimento ainda restrito ao escopo investigativo proposto. Como aqui exploramos o modus operandi de prossumidores caracterizados pelo alto envolvimento com os produtos, entendemos que explorar como sua capacidade de desempenho afeta a reconstrução dos sentidos, ou ainda como outras formas de prossumidores atuam, possa trazer contribuições para o entendimento desses novos cenários. Por outro lado, a ampliação do escopo da pesquisa para além de desvelar os saberes envolvidos nesse campo certamente alargaria o entendimento da prática desses prossumidores. Uma rizoanálise, por exemplo, possibilitaria revelar a multiplicidade de conexões entre cadeias semióticas, organizações do diagrama de forças e circunstâncias sociais (Masny, 2013), e não apenas rastrear seus efeitos.

Como limitação do estudo enxergamos que algumas informações importantes podem ter sido perdidas no tempo, uma vez que esses espaços sociais estão sempre em mudança: perfis são fechados, meios entram em desuso, mídias apagam as postagens em poucas horas etc. Contudo, minimizamos essa condição efetuando a coleta nas mais variadas mídias sociais. Tendo em vista que as informações dos fandoms são sempre replicadas por vários meios, acreditamos que essa condição não tenha prejudicado a investigação.

Por fim, entendemos que analisar o processo do consumo produtivo pela lente do pensamento deleuziano nos permitiu elucidar a importância de se observar como o conhecimento produzido nas margens, em determinado espaço relacional, assume um papel perturbador e produtivo para construção da realidade de todos os envolvidos. Acreditamos que o estudo propiciou um reconhecimento da importância social do fenômeno da prossumerização, como também um aprofundamento do entendimento particular de agenciamento que tem ocupado e transformado os espaços sociais interligados por tecnologias. De forma mais ampla, pela própria construção dessa pesquisa, esperamos ter contribuído com a abordagem crítica da CCT.

\section{Agradecimentos}

Agradecemos ao Conselho Nacional de Desenvolvimento Científico e Tecnológico (CNPq) pelo fomento ao projeto de pesquisa que deu origem a este trabalho. Agradecemos ainda as relevantes contribuições efetuadas pelos avaliadores dessa revista para melhoria do trabalho.

\section{Referências}

Almeida, J. (2003). Estudos deleuzianos da linguagem. Campinas: Editora Unicamp. Amaral, A., Souza, R. V., \& Monteiro, C. (2015). De westeros no \#vemprarua à shippagem do beijo gay na TV brasileira. Ativismo de fãs: conceitos, resistências e práticas na cultura digital. Galáxia, 29, (versão eletrônica), 141-154. 
consumption. Marketing Theory, 16(3), 383-400.

Arnould, E. J., \& Thompson, C. J. (2005). Consumer culture theory (CCT): twenty years of research. Journal of Consumer Research, 31(4), 868-882.

Batista, J., \& Domingos, A. A. (2011, maio). Storytelling e Transtorytelling na saga de Harry Potter. Anais do Congresso de Ciências da Comunicação na Região Sudeste - Intercom, São Paulo, SP, Brasil, 16.

Bauer, M., \& Aarts, B. (2010). A construção do corpus: um princípio para a coleta de dados qualitativos. In: Bauer M., \& Gaskel G. (Eds.). Pesquisa qualitativa com texto, imagem e som: um manual prático. Petrópolis: Vozes.

Beckett, A. (2012). Governing the consumer: technologies of consumption. Consumption Markets \& Culture, 15(1), 1-18.

Belk, R. W., Ger, G., \& Askegaard, S. (2003). The fire of desire: A multisited inquiry into consumer passion. Journal of Consumer Research, 30(3), 326-351.

Bennett, L. (2014). Tracing Textual Poachers: Reflections on the development of fan studies and digital fandom. Journal of Fandom Studies, 2(1), 5-20.

Boulaire, C., \& Cova, B. (2013). The dynamics and trajectory of creative consumption practices as revealed by the postmodern game of geocaching. Consumption Markets \& Culture, 16(1), 1-24.

Bronwen, T. (2011). What is fanfiction and why are people saying such nice things about it? Journal of Narrative Studies, 3, 1-24.

Büscher, B. (2013). 'Prosuming' conservation? Web 2.0, nature and the intensification of value-producing labour in late capitalism. Journal of Consumer Culture, 13 (3), 283-305.

Camargo, T. I., \& Leão, A. L. M. S. (2015a). Pulando a cerca ponto com: a opinião pública sobre a mercantilização do adultério. Organizações \& Sociedade, 22(74), 443-463.

Camargo, T. I., \& Leão, A. L. M. S. (2015b). Pague e pegue: uma arqueologia do discurso do adultério mercadorizado. Revista de Administração Contemporânea, 19(6), 732-811.

Casotti, L. M., \& Suarez, M. C. (2016). Dez anos de Consumer Culture Theory: delimitações e aberturas. Revista de Administração de Empresas, 56(3), 353-359.

Chin, B. (2014). Sherlockology and galactica.tv: fan sites as gifts or exploited labor? Fandom and/as Labor. Transformative Works and Cultures, 15. Retrieved March 29, 2014, from http://journal.transformativeworks.org/index.php/twc/article/view/513

Costa, F. Z. N., \& Leão, A. L. M. S. (2011). Desvelamento do limiar discursivo de uma marca global em uma cultura local. Cadernos EBAPE, 9(2), 299-332.

Costa, F. Z. N., \& Leão, A. L. M. S. (2012). Formações discursivas de uma marca global num contexto local: um estudo inspirado no método arqueológico de Michel Foucault. Organização \& Sociedade, 19(62), 453-469.

Corazza, S. M. (2012). Contribuições de Deleuze e Guattari para as pesquisas em educação. Revista Digital do Laboratório de Artes Visuais, 8, 1-19.

Cova, B., \& Cova, V. (2012). On the road to prosumption: marketing discourse and the development of consumer competencies. Consumption Markets \& Culture, 15(2), 149-168. 
DeLanda, M. (2006). Deleuzian ontology: A sketch. Выпуск, 2(38). Retrieved August 20, 2018, from http://www.situation.ru/app/j_art_1078.htm.

Deleuze, G. (2008). Conversações. São Paulo: Ed.

Deleuze. G. (2002). Espinosa: filosofia prática. São Paulo: Escuta.

Deleuze, G. (1978). Spinoza: Cours Vincennes. Retrieved January30, 2015, from http:// archives.skafka.net/alice69/doc/Deleuze\%20-\%20cours_vincennes_1978-1981. pdf.

Deleuze, G. (1976). Nietzsche e a filosofia. Rio de Janeiro: Editora Rio.

Deleuze, G. \& Guattari, F. (1990). Mil Platôs: capitalismo e esquizofrenia (Vol. 3). Rio de Janeiro: Editora 34.

Deleuze, G. \& Guattari, F. (1997). Mil Platôs: capitalismo e esquizofrenia (Vol. 5). São Paulo: Editora 34.

Deleuze, G. \& Guattari, F. (2010). O Anti-Édipo: capitalismo e esquizofrenia (Vol. 1). São Paulo: Editora 34.

Dujarier, M. A. (2016). The three sociological types of consumer work. Journal of Consumer Culture, 16(2), 555-571.

Earley, A. (2013). Connecting contexts: a badiouian epistemology for consumer culture theory. Marketing Theory, 14(1), 73-96.

Eden, S. (2015). Blurring the boundaries: Prosumption, circularity and online sustainable consumption through Freecycle. Journal of Consumer Culture, 17(2), 265-285.

Ellsworth-Krebs, K., \& Reid, L. (2016). Conceptualising energy prosumption: Exploring energy production, consumption and microgeneration in Scotland, UK. Environment and Planning A, 48(10), 1-14.

Flick, U. (2009). Introdução à pesquisa qualitativa. Bookman/Artmed: Porto Alegre.

Fuchs, C. (2011). Web 2.0, Prosumption, and Surveillance. Surveillance \& Society, 8(3), 288-309.

Foucault, M. (2009). A Arqueologia do Saber. Rio de Janeiro: Forense Universitária.

Gaião, B. F. S., Souza, I. L., \& Leão, A. L. M. S. (2012). Consumer Culture Theory (CCT) já é uma escola de pensamento em marketing? RAE, 52(3), 330-344.

Guschwan, M. (2012). Fandom, brandom and the limits of participatory culture. Journal of Consumer Culture, 12(1), 19-40.

Hardt, M. (1996). Um aprendizado em filosofia. São Paulo: Editora 34.

Heilbrunn, B. (2015). Chaosmosis: french thought styles and the possible reactivation of consumer culture theory. Consumer Culture Theory, 17, 25-45.

Inocêncio, L., Cavalcanti, G., \& Izidio, A. R. (2014, outubro). De Hogwarts para o fandom: narrativa transmídia e o entretenimento como experiência para os fãs da saga Harry Potter. Anais do Congresso de Ciências da Comunicação e Consumo. São Paulo, SP, Brasil, 04.

International Trade Administration (2016). Top Markets Report: Media and Entertainment: A market assessment tool for U.S. exporters. U.S. Department of Commerce, October 2016. Retrieved Jan. 01, 2017, from http://www.trade.gov/ topmarkets/pdf/Media_and_Entertainment_Brazil.pdf.

Jackson, A. Y. (2013) Spaces of power/knowledge: a Foucauldian methodology for qualitative inquiry. Qualitative Inquiry, 19(10), 839-847. 
Jenkins, H. (2009). Cultura da Convergência: A colisão entre os velhos e os novos meios de comunicação. São Paulo: Ed. Aleph.

Kähr, A., Nyffenegger, B., Krohmer, H., \& Hoyer, W. D. (2016). When hostile consumers wreak havoc on your brand: the phenomenon of consumer brand sabotage. Journal of Marketing, 80(3), 25-41.

Laerke, M. (2005). Gilles Deleuze e o sistema da natureza e da filosofia. Alegrar, 2, 1-16.

Lee, H. (2011). Participatory media fandom: a case study of anime fansibbing. Media, Culture \& Society, 33(8), 1131-1147.

Linstead, S., \& Thanem, T. (2007). Multiplicity, virtuality and organization: the contribution of Gilles Deleuze. Organization Studies, 28(10), 1483-1501.

Machado, R. (2010). Deleuze, a arte a filosofia. Rio de Janeiro: Zahar.

Machado, R. (2011). Zaratustra: Tragédia nietzschiana. Rio de Janeiro: Zahar

Madarasz, N. (2005). A potência para simulação: Deleuze, Nietzsche e os desafios figurativos ao se repensar os modelos da filosofia concreta. Educação \& Sociedade, 26(93), 1209-1216.

Masny, D. (2013). Rhizoanalytic pathways in qualitative research. Qualitative Inquiry, 19(5), 339-348.

Mikkonen, I., Moisander, J., \& Firat, A. F. (2011). Cynical identity projects as consumer resistance: The Scrooge as a social critic? Consumption Markets \& Culture, 14(1), 99-116.

Misoczky, M. C. (2003, setembro). Pelo primado das relações nos estudos organizacionais: algumas indicações a partir de leituras enamoradas de Marx, Bourdieu e Deleuze. Anais do Encontro Nacional dos Programas de Pós-Graduação em Administração, Atibaia, SP, Brasil, 27.

Moisander, J., Valtonen, A., \& Hirsto, H. (2009). Personal interviews in cultural consumer research: post-structuralist challenges. Consumption Markets \& Culture, 12(4), 329-348.

Nietzsche, F. (2011). A vontade de poder. Rio de Janeiro: Contraponto.

Paiva, F. G. Jr., Leão, A. L. M. S., \& Mello, S. C. B. (2011). Validade e confiabilidade na pesquisa qualitativa em Administração. Revista de Ciências da Administração, 13(31), 190-209.

Parmentier, M., \& Ficher, E. (2015). Things fall apart: The dynamics of brand audience dissipation. Journal of Consumer Research, 41(5), 1228-1251.

Pongsakornrungsilp, S., \& Schroeder, J. E. (2011). Understanding value co-creation in a co-consuming brand community. Marketing Theory, 11(3), 303-324.

Rey, P. J. (2012). Alienation, exploitation, and social media. American Behavioral Scientist, 56(4), 399-420.

Ritzer, G. (2013). Prosumption: evolution, revolution, or eternal return of the same? Journal of Consumer Culture, 14(1), 3-24.

Ritzer, G. (2015ª). Hospitalidade e prossumerização. Revista Hospitalidade. 12 (Edição Especial), 12 - 41.

Ritzer, G. (2015b). Automating prosumption: the decline of the prosumer and the rise of the prosuming machines. Journal of Consumer Culture, 15(3), 407-424. 
Roberts, J. M. (2017). Prosumer culture and the question fetishism. Journal of Consumer Culture (pp.1-30). Retrieved May 29, 2017, from http://bura.brunel.ac.uk/ handle/2438/14159.

Rolnik, S. (1995, Novembro). Ninguém é deleuziano. O Povo, Caderno Sábado. Recuperado em 5 janeiro, 2017, de https://www.pucsp.br/nucleodesubjetividade/ Textos/SUELY/ninguem.pdf

Ruckenstein, M. (2015). Playing Nintendogs: desire, distributed agency and potentials of prosumption. Journal of Consumer Culture, 15(3), 351-370.

Silva, M. C. (2014). A escola como primado da representação: as contribuições do pensamento de Gilles Deleuze. Conjectura: Filos. Educ., 19(1), 157-172.

Siuda, P. (2014). Fan Cultures: On the Impossible Formation of Global and Transnational Fandoms. In: A. M. Fellner, S. Hamscha, J. Heissenberguer, \& J. J. Moss (Eds.). Is It 'Cause It's Cool? (pp.295-318) Affective Encounters with American Culture. Krotenthallergasse: LIT Verlag Münster.

Souza, E. M., Junquilho, G. S., Machado, L. D., \& Bianco, M. F. (2006). A analítica de Foucault e suas implicações nos estudos organizacionais sobre poder. Organizações \& Sociedade, 13(36), 13-25.

Spaaij, R., \& Viñas, C. (2013). Political ideology and activism in football fan culture in Spain: a view from the far left. Soccer \& Society, 14(2), 183-200.

Spinoza, B. (2009) Ética. Belo Horizonte: Autêntica.

Stanfill, M., \& Condis, M. (2014). Fandom and/as labor [editorial]. Transformative Works and Cultures, 15. Retrieved March 29, 2014, from http://journal.transformativeworks. org/index.php/twc/article/view/593/.

Tórtora, S. (2008). A vontade de potência: a grande política, arte e política em Nietzsche, apontamentos de um estudo inicial. Aurora, 2, 134-155.

Troye, S. V., \& Supphellen, M. (2012). Consumer Participation in Coproduction: "I made it myself": effects on consumers' sensory perceptions and evaluations of outcome and input product. Journal of Marketing, 76(2), 33-46.

Tugendhat, E. (2002). Nietzsche e o problema da transcendência imanente. Ethic@, 1(1), 47-62.

Van Zoonen, L. (2004). Imagining the fan democracy. European Journal of Communication, 19(1), 39-52.

Vargo, S. L., \& Lusch, R. F. (2004). Evolving toward a new dominant logic for marketing. Journal of Marketing, 68(1), 1-17.

Vasconcellos, J. (2010). Teatro e filosofia em Gilles Deleuze. Artefilosofia, 9, 101-108.

Williams, J. (2012). Pós-estruturalismo. Petrópolis: Vozes.

Wood, M., \& Ferlie, E. (2003). Journeying from Hippocrates with Bergson and Deleuze. Organization Studies, 24(1), 47-68.

Zajc, M. (2015). Social media, prosumption, and dispositives: New mechanisms of the construction of subjectivity. Journal of Consumer Culture, 15(1), 28-47.

Zwick, D., \& Knott, J. D. (2009). Manufacturing customers: the database as new means of production. Journal of Consumer Culture, 9(2), 221-247. 